\title{
Barrier Layer Development Local to Tropical Cyclones based on Argo Float Observations
}

\author{
JOHN STEFFEN AND MARK BOURASSA \\ Department of Earth, Ocean and Atmospheric Science, and Center for Ocean-Atmospheric Prediction Studies, \\ Florida State University, Tallahassee, Florida
}

(Manuscript received 13 December 2017, in final form 16 July 2018)

\begin{abstract}
The objective of this study is to quantify barrier layer development due to tropical cyclone (TC) passage using Argo float observations of temperature and salinity. To accomplish this objective, a climatology of Argo float measurements is developed from 2001 to 2014 for the Atlantic, eastern Pacific, and central Pacific basins. Each Argo float sample consists of a prestorm and poststorm temperature and salinity profile pair. In addition, a no-TC Argo pair dataset is derived for comparison to account for natural ocean state variability and instrument sensitivity. The Atlantic basin shows a statistically significant increase in barrier layer thickness (BLT) and barrier layer potential energy (BLPE) that is largely attributable to an increase of $2.6 \mathrm{~m}$ in the post-TC isothermal layer depth (ITLD). The eastern Pacific basin shows no significant changes to any barrier layer characteristic, likely due to a shallow and highly stratified pycnocline. However, the near-surface layer freshens in the upper $30 \mathrm{~m}$ after TC passage, which increases static stability. Finally, the central Pacific has a statistically significant freshening in the upper $20-30 \mathrm{~m}$ that increases upper-ocean stratification by $\sim 35 \%$. The mechanisms responsible for increases in BLPE vary between the Atlantic and both Pacific basins; the Atlantic is sensitive to ITLD deepening, while the Pacific basins show near-surface freshening to be more important in barrier layer development. In addition, Argo data subsets are used to investigate the physical relationships between the barrier layer and TC intensity, TC translation speed, radial distance from TC center, and time after TC passage.
\end{abstract}

\section{Introduction}

Turbulent mixing, localized upwelling, and the entrainment of cooler thermocline water cause the ocean mixed layer (OML) and sea surface temperature (SST) to cool during tropical cyclone (TC) passage (Fisher 1958; Leipper 1967; Elsberry et al. 1976; Price 1981). A negative feedback between upper-ocean cooling and TC intensity occurs due to a reduction in the enthalpy flux from the ocean to the atmosphere (Chang and Anthes 1978; Price 1981; Bender et al. 1993; Schade and Emanuel 1999; Schade 2000; Lloyd and Vecchi 2011). Previous observational studies on TC air-sea interactions have focused on the thermodynamic response (Price 1981; Shay et al. 2000; Cione and Uhlhorn 2003; D'Asaro et al. 2007; Dare and McBride 2011) and dynamic response (Sanford et al. 1987; Price et al. 1994; Morozov and Velarde 2008; Jaimes and Shay 2010; Sanford et al. 2011) of the ocean to TC forcing. Meanwhile, characterizing the upper-ocean salinity response and its

\footnotetext{
Corresponding author: John Steffen, jsteffen@fsu.edu
}

influence on ocean stratification has garnered less attention (Jacob and Koblinsky 2007; Jourdain et al. 2013; Domingues et al. 2015). By using collocated Argo float profiles of temperature and salinity with TC best track data, we conduct a basin-specific analysis of salinity-driven barrier layer development local to TCs.

The presence of a preexisting ocean barrier layer can limit the vertical mixing and SST-cooling response by as much as $0.4^{\circ}-0.8^{\circ} \mathrm{C}$ day $^{-1}$ (Wang et al. 2011). This barrier layer effect results in a more favorable ocean state for TC maintenance (Balaguru et al. 2012), as the mixed layer and thermocline are decoupled. To erode a barrier layer, a sufficient amount of turbulent kinetic energy is required to mix near-surface water down to the thermocline (Chi et al. 2014).

The disturbed ocean state from a TC has a cooler and deeper mixed layer. In addition, a TC can produce precipitation rates as high as $12 \mathrm{~mm} \mathrm{~h}^{-1}$ (Lonfat et al. 2004) that lower sea surface salinity (SSS) values by as much as 0.3 PSU (Jacob and Koblinsky 2007). The combination of a deeper isothermal layer depth (ITLD) and fresher near-surface layer can result in the creation 


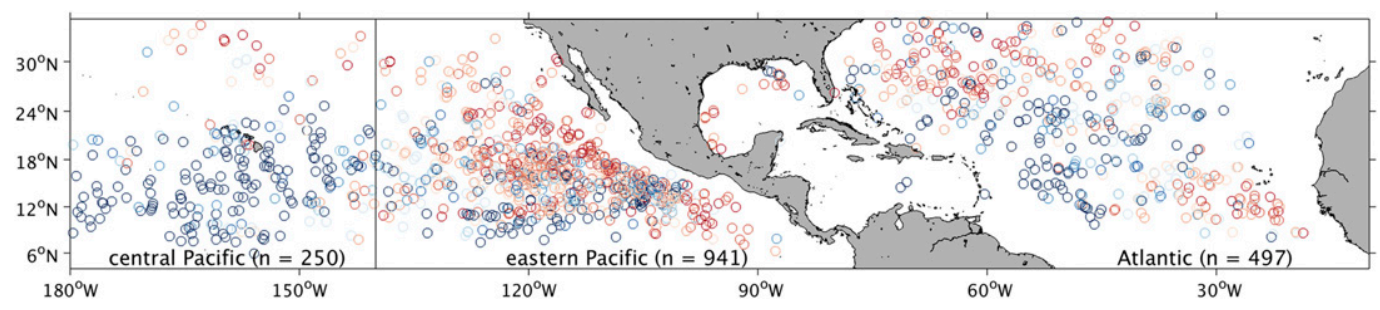

FIG. 1. Argo float profile locations for pre-TC observations from 2001 to 2014 in the Atlantic, eastern Pacific, and central Pacific TC basins. The number of Argo profile samples $n$ for each basin is listed. Argo floats plotted in red (blue) indicate BLPE values below (above) $600 \mathrm{~J} \mathrm{~m}^{-2}$, with dark red profiles approaching $0 \mathrm{~J} \mathrm{~m}^{-2}$ and dark blue profiles $>1200 \mathrm{~J} \mathrm{~m}^{-2}$.

of a barrier layer within and directly after TC passage. In addition, any subsequent storms that interact with the remnants of the SST cold wake may be impacted (Brand 1971; Balaguru et al. 2014, Baranowski et al. 2014).

This analysis focuses on observed TC-induced changes in upper-ocean temperature and salinity, which affect ocean stratification. We construct a climatology of barrier layer characteristics before and after TC passage using Argo float profiles. Our results show that the primary mechanism of barrier layer development in the Atlantic basin is ITLD deepening. In contrast, the eastern and central Pacific basins have slight ITLD shoaling since turbulent mixing is often confined to the layer above the ITLD. In the eastern Pacific, strong stratification at the thermocline limits entrainment. In the central Pacific, the ITLD is climatologically deeper, so only the strongest TCs induce turbulent mixing down to the thermocline. Therefore, near-surface freshening is the dominant mechanism for barrier layer development in both Pacific basins.

A description of the Argo data, along with its limitations, and methods for defining the barrier layer are provided in sections 2 and 3, respectively. Interannual variability related to El Niño-Southern Oscillation (ENSO) ocean states is examined within the TC-Argo float dataset. ENSO-related influences on barrier layer characteristics are explored in section 4. Basin-specific results for the ocean state response to TC passage are discussed in section 5. ITLD deepening and near-surface freshening are discussed as the dominant mechanisms of barrier layer development local to TCs in section 6 . Finally, section 7 summarizes key TC-induced barrier layer findings and highlights the use of the Argo float network as a means to monitor the upper-ocean response to TCs.

\section{Argo float observations}

Argo float profiles of temperature and salinity are obtained for both pre-TC and post-TC ocean states in the Atlantic, eastern Pacific, and central Pacific basins for the period 2001-14 (Argo 2000). Pre-TC Argo float locations are color coded based on barrier layer potential energy (BLPE) values, where $0-600 \mathrm{~J} \mathrm{~m}^{-2}$ (from dark to light red) and $600-1200 \mathrm{~J} \mathrm{~m}^{-2}$ (from light to dark blue) represent varying strengths of the barrier layer (Fig. 1). Several key features appear in the BLPE spatial distribution. First, a peak in BLPE associated with the Orinoco and Amazon River plumes is present in the eastern Caribbean Sea and western half of the Atlantic basin's TC main development region (MDR). Second, a latitudinal pattern in BLPE exists in the eastern Pacific, where higher BLPE is present near the climatological location of the intertropical convergence zone (ITCZ). Smaller values of BLPE are more prevalent in the rain-limited areas to the north. Third, BLPE values are generally the largest in the central Pacific basin due to substantially deeper ITLDs than the other two basins.

All Argo float profiles consist of delayed mode, quality controlled data. Ocean temperatures are accurate to $\pm 0.002^{\circ} \mathrm{C}$, pressures to within $\pm 2.4 \mathrm{dbar}$, and salinities to within \pm 0.01 PSU (Carval et al. 2014). Additional restrictive measures are taken to select pre-TC and post-TC Argo float pairs (Park et al. 2005; Wu and Chen 2012; Fu et al. 2014):

- Profiles are measured by the same Argo float as determined by the float identification.

- Measurements are made within \pm 10 days and a 250-km radius of TC passage based on HURDAT2 best track from the National Hurricane Center.

- Only Argo pairs within $100 \mathrm{~km}$ of each other are selected.

- Vertical sampling must be at least every $10 \mathrm{~m}$ within upper ocean $(<50 \mathrm{~m})$.

- No repeating profiles for a single TC event are selected (removes high-frequency Argo float measurements).

- Argo pair locations are confined to tropical and subtropical latitudes $\left(<35^{\circ} \mathrm{N}\right)$.

To isolate TC-dependent changes from Argo float sensitivity to the background upper-ocean variability, a no-TC Argo pair distribution is constructed for comparison 

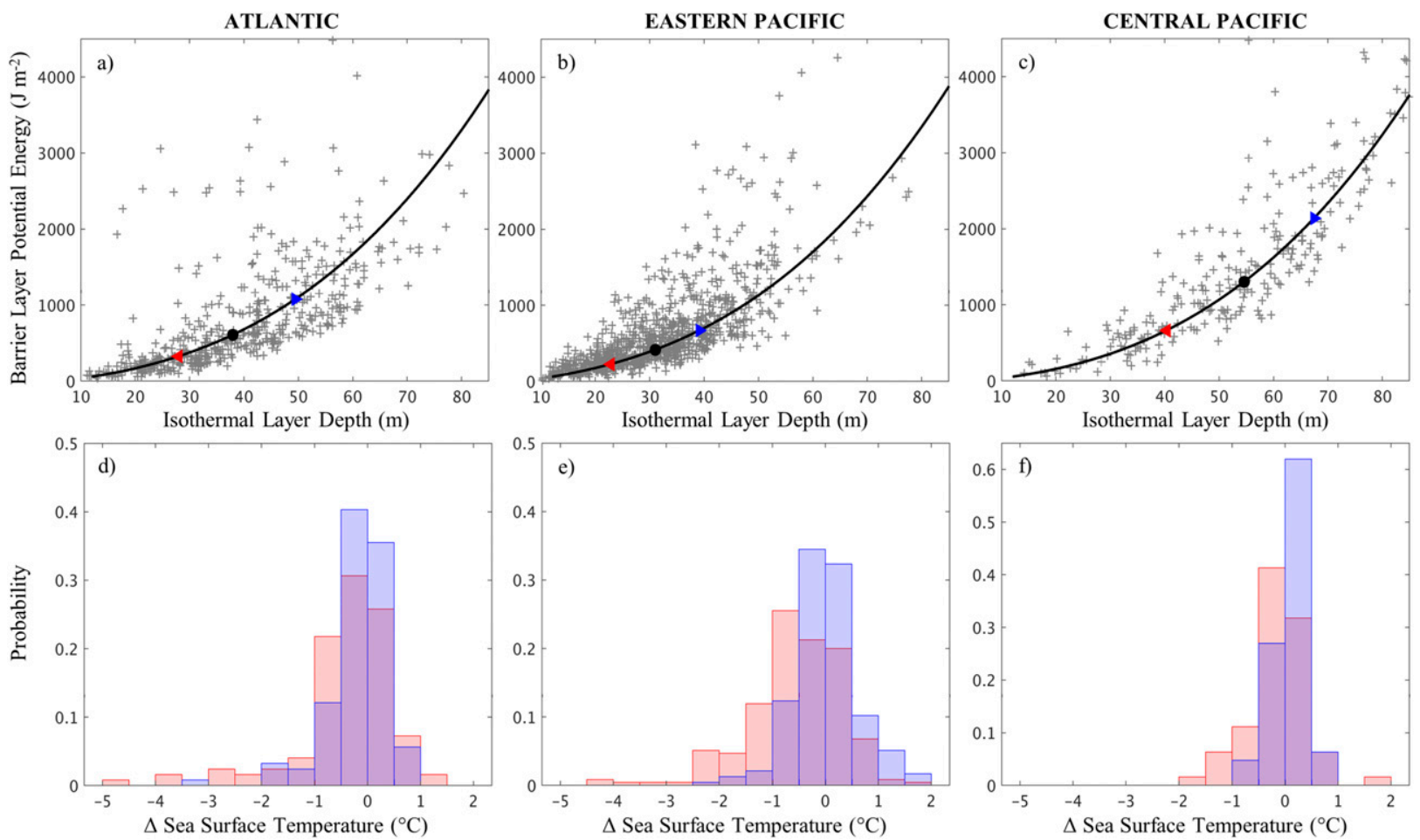

FIG. 2. (a)-(c) Argo float BLPE values as a function of ITLD for pre-TC ocean states in the (left) Atlantic, (center) eastern Pacific, and (right) central Pacific TC basins. The black curve represents BLPE values using the middle 50th percentile of linearized temperature and salinity. Black circles mark the mean ITLD with the red and blue pointers indicating the 25th and 75th percentiles. (d)-(f) Probabilities of the sea surface temperature response to translating TCs for Argo float profiles with ITLD values below the 25th percentile (red) and above the 75 th percentile (blue).

(Fu et al. 2014). No-TC Argo pairs are consecutive ocean profiles taken by the same Argo float that are greater than \pm 10 days and/or $500 \mathrm{~km}$ of TC passage. Additionally, the no-TC Argo pair locations must be within $100 \mathrm{~km}$ of the TC pairs to limit spatial heterogeneity between the distributions and to make the sample sizes comparable ( $\mathrm{Wu}$ and Chen 2012).

Using the Argo float network to analyze TC air-sea interactions poses several challenges. First, Argo data sampling within the Caribbean Sea and Gulf of Mexico is sparse (Fig. 1). Therefore, results for the Atlantic basin are more representative of conditions in the main development region and to the north and west, as TCs recurve out of the tropics. Second, the sample sizes of Argo float observations vary among the three basins. The eastern Pacific basin has the largest TC pair sample size, but a smaller no-TC pair distribution due to a higher TC spatial density. The central Pacific basin has a smaller sample size than the other TC basins, which increases uncertainty in the mean. Finally, temporal sampling for Argo floats ( $\sim 10$ days) makes analyzing transient, high-impact events, such as TCs difficult. Surface freshwater signatures from precipitation typically persist for two days after TC passage (Jacob and Koblinsky 2007). Therefore, this analysis underestimates the largest salinity-driven impacts to upperocean stratification because we use a 10-day sampling window after TC passage. Despite these issues, the large Argo float sample sizes reveal statistically significant upper-ocean features.

\section{Barrier layer methodology}

Barrier layer thickness (BLT) is a proxy that is often used to quantify the resistance of the upper ocean to turbulent mixing. A thick BLT suppresses the turbulent heat flux across the thermocline and into the ocean mixed layer (Foltz and McPhaden 2009). However, BLT does not account for stratification within the ITLD due to salinity. Therefore, this study uses the BLPE [Eq. (1)] as a direct measure of barrier layer strength because it accounts for changes in stratification within the ITLD (Chi et al. 2014). Large values of BLPE are indicative of a stably stratified, deep isothermal layer (Figs. 2a-c). The response of the near-surface temperature change to translating TCs is highly dependent upon the pre-TC 
ITLD and BLPE magnitudes. The largest cooling responses are generally associated with shallow ITLD and minimal BLPE, while large values of BLPE tend to suppress the cooling response within the TC cold wake (Figs. 2d-f). The BLPE is defined as the difference between the integral of the vertically averaged, fully mixed, density from the ITLD to the surface [PE ${ }_{\text {mix }}$; Eq. (2)] and the same integral using the observed density profile $\left[\mathrm{PE}_{o}\right.$; Eq. (3)] (Chi et al. 2014). In these equations, $g$ is Earth's gravitational acceleration, $\rho(z)$ is the density profile, $\overline{\rho(z)}$ is the depth-averaged density within the ITLD, and $z$ is the depth:

$$
\begin{aligned}
\mathrm{BLPE} & =\mathrm{PE}_{\text {mix }}-\mathrm{PE}_{o}, \\
\mathrm{PE}_{\text {mix }} & =-g \int_{z_{\text {ITLD }}^{0}}^{\rho(z)} z d z, \text { and } \\
\mathrm{PE}_{o} & =-g \int_{z_{\text {ITLD }}^{0}}^{0} \rho(z) z d z .
\end{aligned}
$$

Additionally, we calculate the isopycnal layer depth (IPLD) and ITLD using a threshold method. The IPLD is determined by a potential density $\left(\sigma_{t}\right)$ increase of $0.10 \mathrm{~kg} \mathrm{~m}^{-3}\left(\Delta \sigma_{t}\right)$ from a $10-\mathrm{m}$ reference depth, similar to previous literature (Sprintall and Tomczak 1992; Foltz et al. 2010; Chi et al. 2014). The ITLD threshold is defined as a temperature decrease of $0.5^{\circ} \mathrm{C}$ from the reference depth (Sprintall and Tomczak 1992) as follows:

$$
\sigma_{t(\mathrm{IPLD})}=\sigma_{t(10 \mathrm{~m})}+\Delta \sigma_{t} .
$$

The 10-m reference depth minimizes wave-driven and diurnal changes in temperature and salinity near the surface. Many Argo floats make their first near-surface measurements at 10-m depth.

\section{Threshold criteria sensitivity}

The selection of threshold criteria to define the mixed layer depth can be rather arbitrary (de Boyer Montegut et al. 2004). Many past studies that have analyzed individual ocean profile data define the mixed layer as a potential density increase $\sigma_{\theta}$ of $0.01-0.03 \mathrm{~kg} \mathrm{~m}^{-3}$ (Schneider and Müller 1990; Thomson and Fine 2003), $0.03 \mathrm{~kg} \mathrm{~m}^{-3}$ (Weller and Plueddemann 1996; de Boyer Montegut et al. 2004), $0.05 \mathrm{~kg} \mathrm{~m}^{-3}$ (Brainerd and Gregg 1995), and $0.125 \mathrm{~kg} \mathrm{~m}^{-3}$ (Suga et al. 2004). Other studies define the mixed layer based on temperature threshold criteria $\Delta T$ of $-0.2^{\circ} \mathrm{C}$ (Thompson 1976), $-0.5^{\circ} \mathrm{C}$ (Spall et al. 2000; Foltz et al. 2003), and $-1.0^{\circ} \mathrm{C}$ (Rao et al. 1989). For this study, we test the sensitivity of calculated barrier layer characteristics to different threshold criteria (Table 1). The first column represents the barrier layer values used in this study, based on a $\Delta \sigma_{\theta}$ of $+0.10 \mathrm{~kg} \mathrm{~m}^{-3}$ and a $\Delta T$ of $-0.5^{\circ} \mathrm{C}$ from a 10 -m reference depth. Blank cells (marked with dashes) within Table 1 are unchanged barrier layer values from column 1 . The sensitivity of the potential density threshold is determined while using a constant $\Delta T$ of $-0.5^{\circ} \mathrm{C}$. Likewise, the sensitivity of the temperature threshold is determined while using a constant $\Delta \sigma_{\theta}$ of $+0.10 \mathrm{~kg} \mathrm{~m}^{-3}$.

Depending on the selected threshold values, absolute barrier layer values can vary. For example, using a potential density threshold of $+0.01 \mathrm{~kg} \mathrm{~m}^{-3}$ (which is an order of magnitude less than that selected for this study) reduces the IPLD by about half (Table 1, column 2). This has the effect of reducing variability in IPLD between pre-TC/post-TC Argo pairs and increasing the BLT. In addition, the calculation of BLPE depends on the ITLD and therefore is dependent on the temperature threshold used to calculate ITLD (Table 1, column 5). A temperature criterion of $-0.2^{\circ} \mathrm{C}$ reduces the ITLD and BLPE values by $7.4 \%$ and $35.7 \%$, respectively, when compared to a $\Delta T$ of $-0.5^{\circ} \mathrm{C}$.

The selected potential density and temperature threshold criteria $\left(\Delta \sigma_{\theta}=+0.10 \mathrm{~kg} \mathrm{~m}^{-3} ; \Delta T=-0.5^{\circ} \mathrm{C}\right)$ are appropriate for several reasons. First, the thresholds are consistent with previous barrier layer observational studies (Sprintall and Tomczak 1992; Foltz et al. 2010; Chi et al. 2014) and the values are near the median of threshold criteria used in the ocean mixed layer studies mentioned above. Second, the potential density criterion reveals changes in the IPLD that are largely missed when using a smaller criterion. Third, the temperature criterion is sufficiently large as to minimize false classification of ITLDs due to small ocean temperature fluctuations in Argo float profiles. Also, the forced stage of a TC produces turbulent mixing that can extend down to the ITLD. The temperature threshold used here represents an ITLD where entrainment of subthermocline water into the mixed layer can substantially reduce SST and enthalpy fluxes that affect TC thermodynamics.

While the thickness of the barrier layer can be sensitive to the threshold criteria, changes in barrier layer characteristics are less affected. Furthermore, the sign of barrier layer changes is consistent among different threshold criteria (Table 1). Therefore, we find that the results presented on TC-induced changes to barrier layer characteristics are qualitatively consistent regardless of the threshold criteria selected.

\section{Interannual variability in Argo pairs}

A major source of interannual variability is due to the El Niño-Southern Oscillation (ENSO) signal and the coupled air-sea interactions that occur between surface 
TABLE 1. Barrier layer characteristics for pre-TC Argo profiles for different potential density and temperature threshold values. Changes in these variables after TC passage are shown in parentheses. Variables that are unaffected by changes in potential density thresholds (BLPE and ITLD) or temperature thresholds (IPLD) are indicated by dashes.

\begin{tabular}{|c|c|c|c|c|c|}
\hline & $\begin{array}{c}\Delta \sigma_{\theta}=0.10 \mathrm{~kg} \mathrm{~m}^{-3} \\
\Delta T=-0.5^{\circ} \mathrm{C}\end{array}$ & $\begin{array}{c}\Delta \sigma_{\theta}=0.01 \mathrm{~kg} \mathrm{~m}^{-3}, \\
\Delta T=-0.5^{\circ} \mathrm{C}\end{array}$ & $\begin{array}{c}\Delta \sigma_{\theta}=0.05 \mathrm{~kg} \mathrm{~m}^{-3} \\
\Delta T=-0.5^{\circ} \mathrm{C}\end{array}$ & $\begin{array}{c}\Delta \sigma_{\theta}=0.125 \mathrm{~kg} \mathrm{~m}^{-3} \\
\Delta T=-0.5^{\circ} \mathrm{C}\end{array}$ & $\begin{array}{c}\Delta \sigma_{\theta}=0.10 \mathrm{~kg} \mathrm{~m}^{-3} \\
\Delta T=-0.2^{\circ} \mathrm{C}\end{array}$ \\
\hline \multicolumn{6}{|c|}{ Atlantic } \\
\hline $\operatorname{BLPE}\left(\mathrm{J} \mathrm{m}^{-2}\right)$ & $887.9(+130.2)$ & - & - & - & $602.7(+111.7)$ \\
\hline $\operatorname{BLT}(\mathrm{m})$ & $14.3(+2.6)$ & $27.3(+3.3)$ & $20.7(+3.1)$ & $11.8(+2.2)$ & $11.4(+2.3)$ \\
\hline $\operatorname{IPLD}(\mathrm{m})$ & $24.8(+0.8)$ & $11.8(+0.1)$ & $18.4(+0.3)$ & $27.4(+1.2)$ & - \\
\hline ITLD (m) & $39.1(+3.4)$ & - & - & - & $37.2(+2.9)$ \\
\hline \multicolumn{6}{|c|}{ Eastern Pacific } \\
\hline $\operatorname{BLPE}\left(\mathrm{J} \mathrm{m}^{-2}\right)$ & $668.5(-29.4)$ & - & - & - & $418.6(-4.6)$ \\
\hline $\operatorname{BLT}(\mathrm{m})$ & $10.1(+0.0)$ & $20.7(-0.3)$ & $15.2(-0.1)$ & $8.3(-0.1)$ & $6.6(+0.5)$ \\
\hline $\operatorname{IPLD}(\mathrm{m})$ & $21.7(-0.4)$ & $11.1(-0.0)$ & $16.6(-0.2)$ & $23.6(-0.3)$ & - \\
\hline ITLD (m) & $31.8(-0.3)$ & - & - & - & $29.6(+0.5)$ \\
\hline \multicolumn{6}{|c|}{ Central Pacific } \\
\hline $\operatorname{BLPE}\left(\mathrm{J} \mathrm{m}^{-2}\right)$ & $1752.6(-93.2)$ & - & - & - & $1092.6(-146.4)$ \\
\hline $\operatorname{BLT}(\mathrm{m})$ & $27.4(-0.8)$ & $43.2(-1.8)$ & $35.8(-1.5)$ & $23.6(-0.6)$ & $20.9(-1.7)$ \\
\hline $\operatorname{IPLD}(\mathrm{m})$ & $27.8(-1.0)$ & $12.0(-0.0)$ & $19.4(-0.3)$ & $31.6(-1.2)$ & - \\
\hline ITLD (m) & $55.2(-1.8)$ & - & - & - & $49.4(-2.9)$ \\
\hline
\end{tabular}

winds, equatorial and zonal SST anomalies, and upperocean heat content across the tropical Pacific Ocean (Wang et al. 1999; Willis et al. 2004). Furthermore, ocean-atmosphere ENSO teleconnections influence tropical Atlantic SST variability in several key regions (Enfield and Mayer 1997). Therefore, it is reasonable to expect an interannual ENSO signal to be present in the Argo float profile data for the 2001-14 period used in this study. Based on the oceanic Niño index (ONI), there were three La Niña states $(2007,2010,2011)$, three El Niño states $(2002,2004,2009)$, and eight neutral states (2001, 2003, 2005, 2006, 2008, 2012, 2013, 2014) during the TC season (NOAA Climate Prediction Center 2018). The La Niña years of 2007 and 2010 were particularly strong, with an average ONI of $-1.0^{\circ}$ and $-1.3^{\circ} \mathrm{C}$, respectively. However, the El Niño years were weaker, with average ONI values of $1.0^{\circ}, 0.6^{\circ}$, and $0.7^{\circ} \mathrm{C}$. To resolve the ENSO signal, sufficient Argo data sampling is necessary (Fig. 3). The number of samples during a given year and a given basin relies on two main factors: the number of floats available (size of the Argo float network) and the number of TCs (opportunity to sample TC-induced ocean response). Generally, the number of Argo float samples has increased with time as the Argo float network has expanded, with a noticeable increase in observations of TC-ocean interactions after 2005 . Since $2 / 3$ of El Niño years in this sample occurred before 2005 , when not many observations were

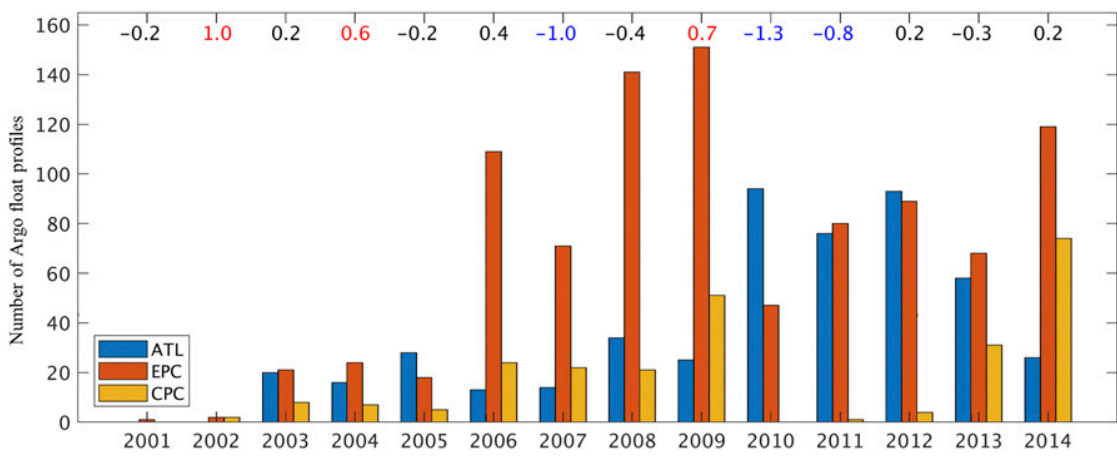

FIG. 3. Histogram of Argo float samples in the Atlantic, eastern Pacific, and central Pacific TC basins from 2001 to 2014. Summertime averages of ONI (3-month running mean of ERSST. v5 SST anomaly) are listed above, where a $\pm 0.5^{\circ} \mathrm{C}$ SST anomaly across the Niño-3.4 region $\left(5^{\circ} \mathrm{S}-5^{\circ} \mathrm{N}, 120^{\circ}-170^{\circ} \mathrm{W}\right)$ characterizes El Niño (red) or La Niña (blue) states (NOAA Climate Prediction Center 2018) 
TABLE 2. Barrier layer metrics of pre-TC ocean profiles (and the TC-induced response) are subset based on the El Niño-Southern Oscillation signals. The number of samples $n$ is listed for each TC basin and ENSO state. Statistically significant differences from neutral conditions at the 95th confidence interval are bolded.

\begin{tabular}{|c|c|c|c|}
\hline & El Niño & La Niña & Neutral \\
\hline Atlantic & $n=41$ & $n=184$ & $n=272$ \\
\hline $\operatorname{BLPE}\left(\mathrm{J} \mathrm{m}^{-2}\right)$ & $787.4(+205.9)$ & 844.8 (+45.1) & $932.1(+176.4)$ \\
\hline $\operatorname{BLT}(\mathrm{m})$ & $\mathbf{1 1 . 3}(+3.1)$ & $\mathbf{1 2 . 7}(+1.7)$ & $15.8(+3.1)$ \\
\hline $\operatorname{IPLD}(\mathrm{m})$ & $21.9(+2.6)$ & $24.2(+0.7)$ & $25.7(+0.6)$ \\
\hline ITLD (m) & $33.2(+5.7)$ & $36.9(+2.4)$ & $41.6(+3.7)$ \\
\hline Eastern Pacific & $n=177$ & $n=198$ & $n=566$ \\
\hline $\operatorname{BLPE}\left(\mathrm{J} \mathrm{m}^{-2}\right)$ & $919.3(-78.3)$ & $463.9(-8.3)$ & $661.7(-21.4)$ \\
\hline $\operatorname{BLT}(\mathrm{m})$ & $12.3(0.0)$ & $7.1(+0.5)$ & $10.4(-0.1)$ \\
\hline $\operatorname{IPLD}(\mathrm{m})$ & $23.2(-0.7)$ & $20.4(-0.5)$ & $21.7(-0.2)$ \\
\hline ITLD (m) & $35.5(-0.7)$ & $27.5(0.0)$ & $32.1(-0.3)$ \\
\hline Central Pacific & $n=60$ & $n=23$ & $n=167$ \\
\hline $\operatorname{BLPE}\left(\mathrm{J} \mathrm{m}^{-2}\right)$ & $1378.1(-14.3)$ & $2252.7(-212.6)$ & $1818.2(-105.1)$ \\
\hline $\operatorname{BLT}(\mathrm{m})$ & $22.1(+1.8)$ & $36.1(-4.4)$ & $28.1(-1.3)$ \\
\hline $\operatorname{IPLD}(\mathrm{m})$ & $27.3(-1.3)$ & $28.3(+1.3)$ & $27.9(-1.2)$ \\
\hline $\operatorname{ITLD}(\mathrm{m})$ & $49.5(+0.5)$ & $64.4(-3.1)$ & $56.0(-2.5)$ \\
\hline
\end{tabular}

available, the El Niño signal is dominated by Argo float observations in 2009 (Fig. 3). The influences of annual TC count variability on Argo float sampling can be seen in the following example; suppressed TC activity from 2010-11 in the central Pacific basin resulted in only one Argo float sample (Fig. 3). Since the 2010-11 period encompasses two La Niña years, the central Pacific TC basin is severely undersampled during La Niña ocean states.

A strong, ENSO-related interannual signal in the pre-TC ocean states exists across all three TC basins. In the Atlantic, barrier layer characteristics are shallower during both El Niño and La Niña when compared to neutral conditions. There is a corresponding reduction in BLPE, yet it is not statistically significant (Table 2). In the eastern Pacific, the barrier layer is deeper and stronger during El Niño years, consistent with anomalously warm upper-ocean temperatures and positive thermocline displacements in this region. Conversely, the barrier layer is shallower and weaker during La Niña years, as SSTs are anomalously cold and the thermocline is shallower. The barrier layer characteristics in the central Pacific have the opposite response to ENSO compared to the eastern Pacific for many of the same arguments related to thermocline displacement. However, a small sample size for the central Pacific resulted in less statistical significance.

Interestingly, the strong ENSO signal present in the pre-TC Argo float profiles is not reflected in TC-induced changes to the barrier layer. This result is not completely unexpected since TC-induced changes to the barrier layer are influenced both by the background ocean state (interannual variability), but also many other factors related to the TC itself (intensity, speed, size) and Argo data sampling (radial distance and time after TC passage). However, some meaningful relationships between TC-ocean interaction and ENSO are still apparent. First, when the background ocean state has a shallower barrier layer structure (Atlantic/El Niño, eastern Pacific/La Niña, central Pacific/El Niño), TC-induced changes often increase the barrier layer. Conversely, the presence of strong preexisting barrier layers in the Pacific TC basins (eastern Pacific/El Niño and central Pacific/La Niña) result in barrier layer reduction in response to a TC. The current, well-developed Argo float network will allow more observations of $\mathrm{TC}$-ocean interaction in the future, and a better-resolved ENSO signal in barrier layer changes may be recoverable.

\section{Basin-specific barrier layer characteristics}

\section{a. Atlantic TC basin}

The Atlantic TC basin shows statistically significant increases at $95 \%$ confidence in all barrier layer metrics after TC passage (Fig. 4). Of the 497 Argo float pairs in the Atlantic basin, BLPE values increase in $63 \%$ of the cases, resulting in an average increase of $130.2 \mathrm{~J} \mathrm{~m}^{-2}$ $(+14.7 \%)$ from pre-TC values. In addition, the ITLD and IPLD deepen by $3.4 \mathrm{~m}(+8.6 \%)$ and $0.8 \mathrm{~m}(+3.2 \%)$, respectively, creating an increase in BLT of $2.6 \mathrm{~m}$ $(+17.9 \%)$ (Fig. 4). BLPE calculated using a constant ITLD between each Argo pair (dashed lines, Fig. 4a) reveals no significant change in pre- and post-TC BLPE values. TC-induced changes in near-surface temperature reveal that $63.7 \%$ of Argo profiles experience cooling, with an average $\Delta$ SST of $-0.65^{\circ} \mathrm{C}$ (Table 3). The remaining $36.1 \%$ of Argo profiles show slight 
ATLANTIC

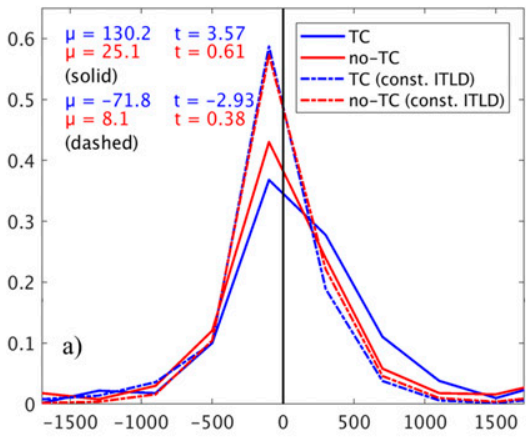

Barrier Layer Potential Energy difference $\left(\mathrm{J} \mathrm{m}^{-2}\right)$

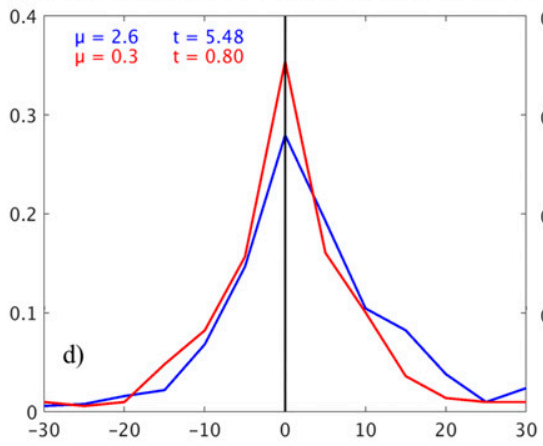

Barrier Layer Thickness difference (m)
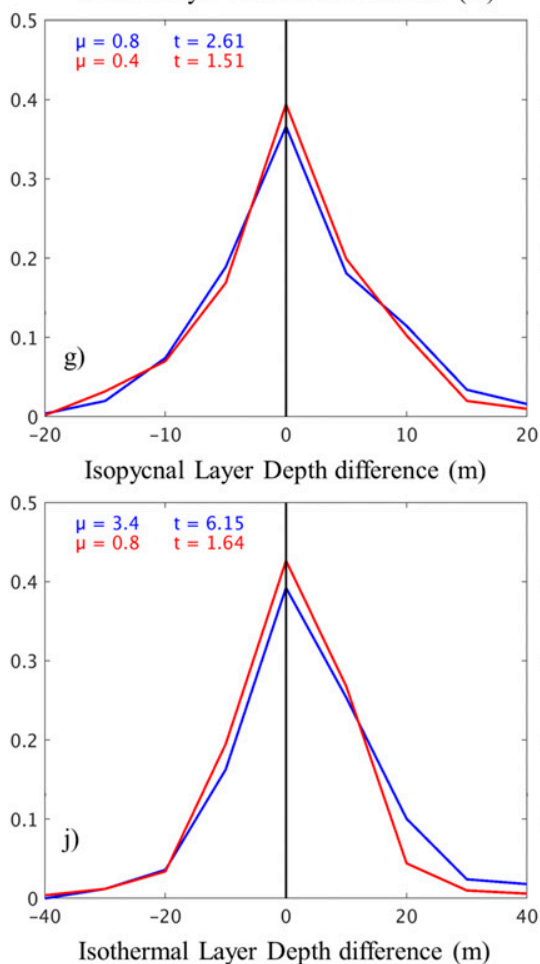

EASTERN PACIFIC

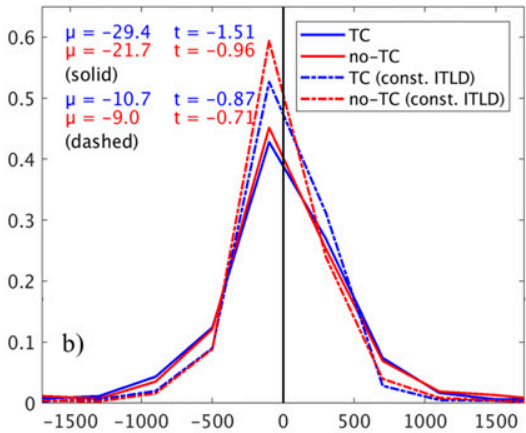

Barrier Layer Potential Energy difference $\left(\mathrm{J} \mathrm{m}^{-2}\right)$

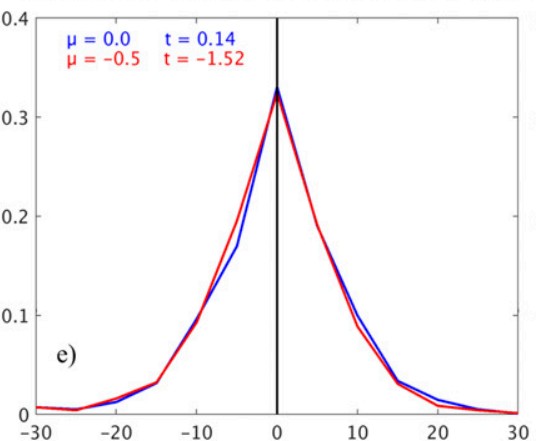

Barrier Layer Thickness difference (m)

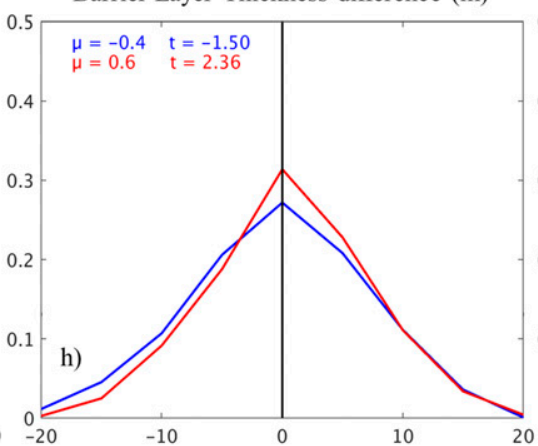

Isopycnal Layer Depth difference $(\mathrm{m})$

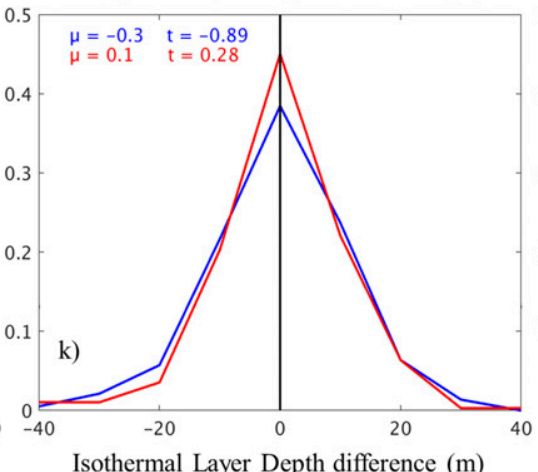

CENTRAL PACIFIC

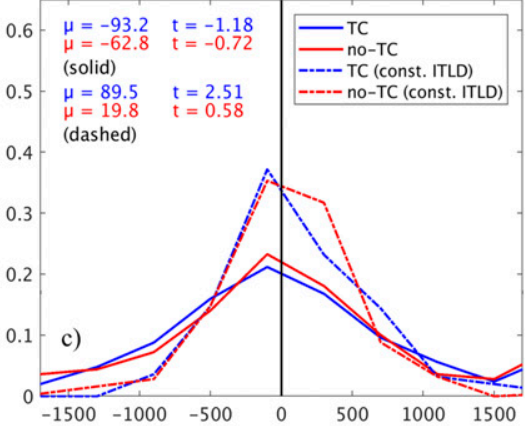

Barrier Layer Potential Energy difference $\left(\mathrm{J} \mathrm{m}^{-2}\right)$

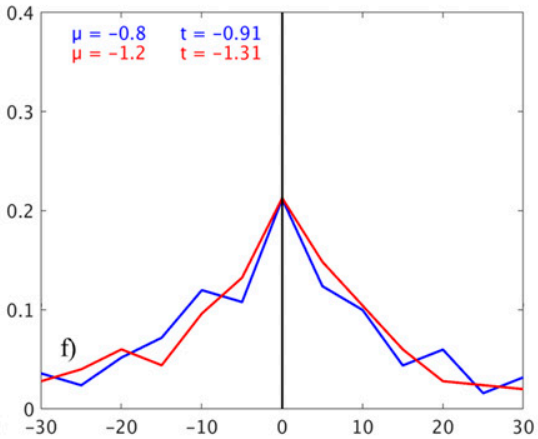

Barrier Layer Thickness difference (m)
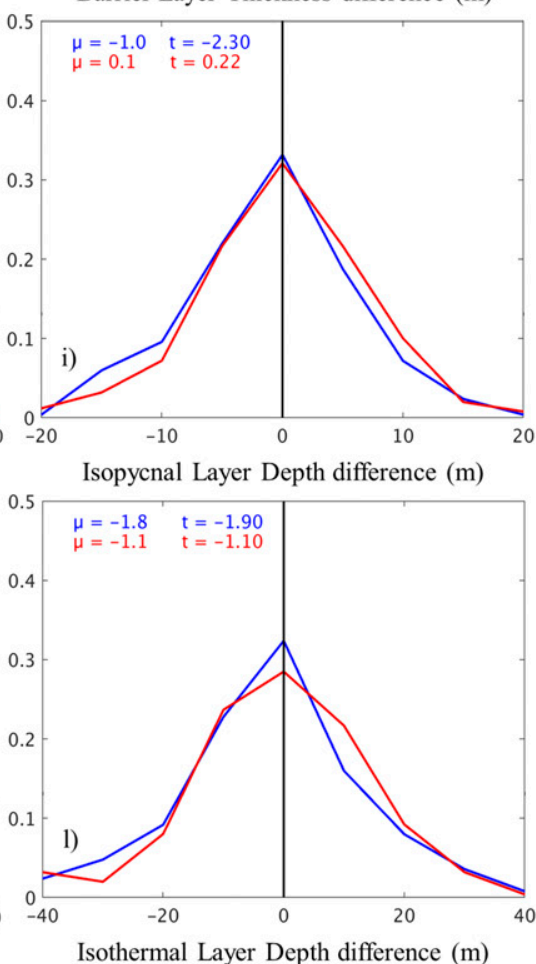

FIG. 4. Normalized histograms of (a)-(c) BLPE, (d)-(f) BLT, (g)-(i) IPLD, and (j)-(l) ITLD using both the TC (blue) and no-TC (red) distributions for the (left) Atlantic, (center) eastern Pacific, and (right) central Pacific TC basins. BLPE values are also calculated using the minimum, constant ITLD between each Argo pair and are shown as dashed lines in (a)-(c). Mean values $\mu$ and Student's $t$-test scores $t$ are listed in the upper left corner of each subplot. Any values of the Student's $t$ test above \pm 1.65 indicate statistical significance at the $95 \%$ level. 
TABLE 3. TC-induced changes in near-surface $(<10 \mathrm{~m})$ temperature and salinity from Argo float observations. The percentage of the total number of Argo profiles is listed in parentheses.

\begin{tabular}{|c|c|c|c|c|c|c|c|c|}
\hline TC basin & $\begin{array}{c}\text { No. of profiles } \\
\text { with }-\Delta \text { SSS }\end{array}$ & $\begin{array}{l}\text { Magnitude of } \\
-\Delta \text { SSS (PSU) }\end{array}$ & $\begin{array}{c}\text { No. of profiles } \\
\text { with }+\Delta \text { SSS }\end{array}$ & $\begin{array}{l}\text { Magnitude of } \\
+\Delta \text { SSS (PSU) }\end{array}$ & $\begin{array}{c}\text { No. of profiles } \\
\text { with }-\Delta S S T\end{array}$ & $\begin{array}{l}\text { Magnitude of } \\
-\Delta \operatorname{SST}\left({ }^{\circ} \mathrm{C}\right)\end{array}$ & $\begin{array}{c}\text { No. of profiles } \\
\text { with }+\Delta S S T\end{array}$ & $\begin{array}{c}\text { Magnitude of } \\
+\Delta \operatorname{SST}\left({ }^{\circ} \mathrm{C}\right)\end{array}$ \\
\hline Atlantic & $243(50.4 \%)$ & -0.16 & $237(49.2 \%)$ & +0.18 & $307(63.7 \%)$ & -0.65 & $174(36.1 \%)$ & +0.27 \\
\hline $\begin{array}{l}\text { Eastern } \\
\text { Pacific }\end{array}$ & $539(58.7 \%)$ & -0.16 & $378(41.1 \%)$ & +0.15 & $545(59.3 \%)$ & -0.65 & $374(40.7 \%)$ & +0.51 \\
\hline $\begin{array}{l}\text { Central } \\
\text { Pacific }\end{array}$ & $135(56.0 \%)$ & -0.13 & $105(43.6 \%)$ & +0.08 & $106(44.0 \%)$ & -0.30 & $134(55.6 \%)$ & +0.28 \\
\hline
\end{tabular}

warming near the surface, with an average $\Delta$ SST of $+0.27^{\circ} \mathrm{C}$. Ocean surface warming in post-TC Argo profiles can occur when a temperature inversion precedes TC passage. Warm subsurface layers are often collocated with strong salinity-driven barrier layers (Cronin and McPhaden 2002). Additionally, the 10-day Argo sampling period can allow for the partial or full recovery to climatological SSTs. For the salinity response, there is an equal likelihood of freshening $(50.4 \%)$ or salinification $(49.2 \%)$ in the near-surface layer (Table 3). Competing processes of freshwater flux from rainfall $(-\Delta \mathrm{SSS})$ and the combination of evaporation and entrainment of saltier water largely cancel salinity changes in the Atlantic TC basin. Therefore, salinity-driven changes to barrier layer metrics are minimal.

The deepened ITLD is primarily responsible for barrier layer development in the Atlantic basin, as opposed to a change in upper-ocean salinity. The vertical profile structure of temperature and salinity for the Atlantic basin supports this result, as turbulent mixing has reduced upper ocean stratification (Fig. 4g). Statistically significant cooling extends to a depth of $\sim 56 \mathrm{~m}$, creating a less stratified ITLD (Fig. 5a). In addition, the salinity decreases from the surface to a depth of $\sim 46 \mathrm{~m}$, but this slight freshening has minimal impact on stratification.

\section{b. Eastern Pacific TC basin}

The eastern Pacific basin shows no statistically significant changes in barrier layer metrics after TC passage. BLPE actually decreases by $-29.4 \mathrm{~J} \mathrm{~m}^{-2}(-4.4 \%)$ in the mean, while both the IPLD and ITLD shoal by $-0.4 \mathrm{~m}(-1.7 \%)$ and $-0.3 \mathrm{~m}(-1.0 \%)$, respectively (Fig. 4). However, BLPE values increase in $50.9 \%$ of the eastern Pacific Argo pairs. Near-surface cooling occurs in $59.3 \%$ of Argo profiles, resulting in an average $\Delta$ SST of $-0.65^{\circ} \mathrm{C}$ (Table 3). Interestingly, in the $40.7 \%$ of Argo profiles that experience warming, the average magnitude of the warming $\left(+0.51^{\circ} \mathrm{C}\right)$ is almost twice as much as seen in the Atlantic $\left(+0.27^{\circ} \mathrm{C}\right)$ and central Pacific $\left(+0.28^{\circ} \mathrm{C}\right)$. The eastern Pacific also has the strongest salinity response, as $58.7 \%$ of Argo profiles experience freshening ( -0.16 PSU) after TC passage (Table 3).

Even with a reduction in barrier layer metrics, the vertical profiles of temperature and salinity reveal cooling throughout the upper $100 \mathrm{~m}$ and freshening in the upper $40 \mathrm{~m}$, which results in a slightly more stable near-surface layer from 0 - to $25-\mathrm{m}$ depth (Fig. 5). There is a statistically significant freshening in the upper $\sim 25 \mathrm{~m}$, and because there is homogeneous cooling throughout the profile, stability $N^{2}$ is affected more by the near-surface salinity change (Fig. 5). As a result, stability increases by $37.0 \%$ in the $0-10-\mathrm{m}$ bin and by $31.6 \%$ in the $10-20-\mathrm{m}$ bin after TC passage. Therefore, for the eastern Pacific basin, near-surface freshening increases stratification, while a reduction in ITLD suppresses barrier layer development.

\section{c. Central Pacific TC basin}

Both the IPLD and ITLD decrease in the mean by $-1.0 \mathrm{~m}(-3.5 \%)$ and $-1.8 \mathrm{~m}(-3.3 \%)$, respectively. Correspondingly, BLT decreases by $-0.8 \mathrm{~m}(-3.0 \%)$ and BLPE by $-93.2 \mathrm{~J} \mathrm{~m}^{-2}(-5.3 \%)$ (Fig. 4). However, the mean BLPE using a constant ITLD result in the opposite response, an increase of $89.5 \mathrm{~J} \mathrm{~m}^{-2}(+7.7 \%)$ after TC passage. The BLPE increase using a constant ITLD indicates that salinity-driven increases in stratification influence BLPE values more than the decrease in ITLD. This result is supported by the temperature and salinity vertical profile structures, which have a more stratified upper ocean. Interestingly, there is very little cooling in the upper $30 \mathrm{~m}$ after TC passage in the central Pacific, likely a consequence of a warm, deep isothermal layer. From depths of $35-100 \mathrm{~m}$, there is a statistically significant temperature decrease, with more cooling at depth. The temperature response actually increases stratification from 35 to $100 \mathrm{~m}$, which is very different from the temperature response in the Atlantic and eastern Pacific basins. Additionally, a strong salinity signal is present in the upper $20 \mathrm{~m}$, with a near-surface fresh layer developing. Stratification increases throughout the entire 100-m profile due to both the temperature and 

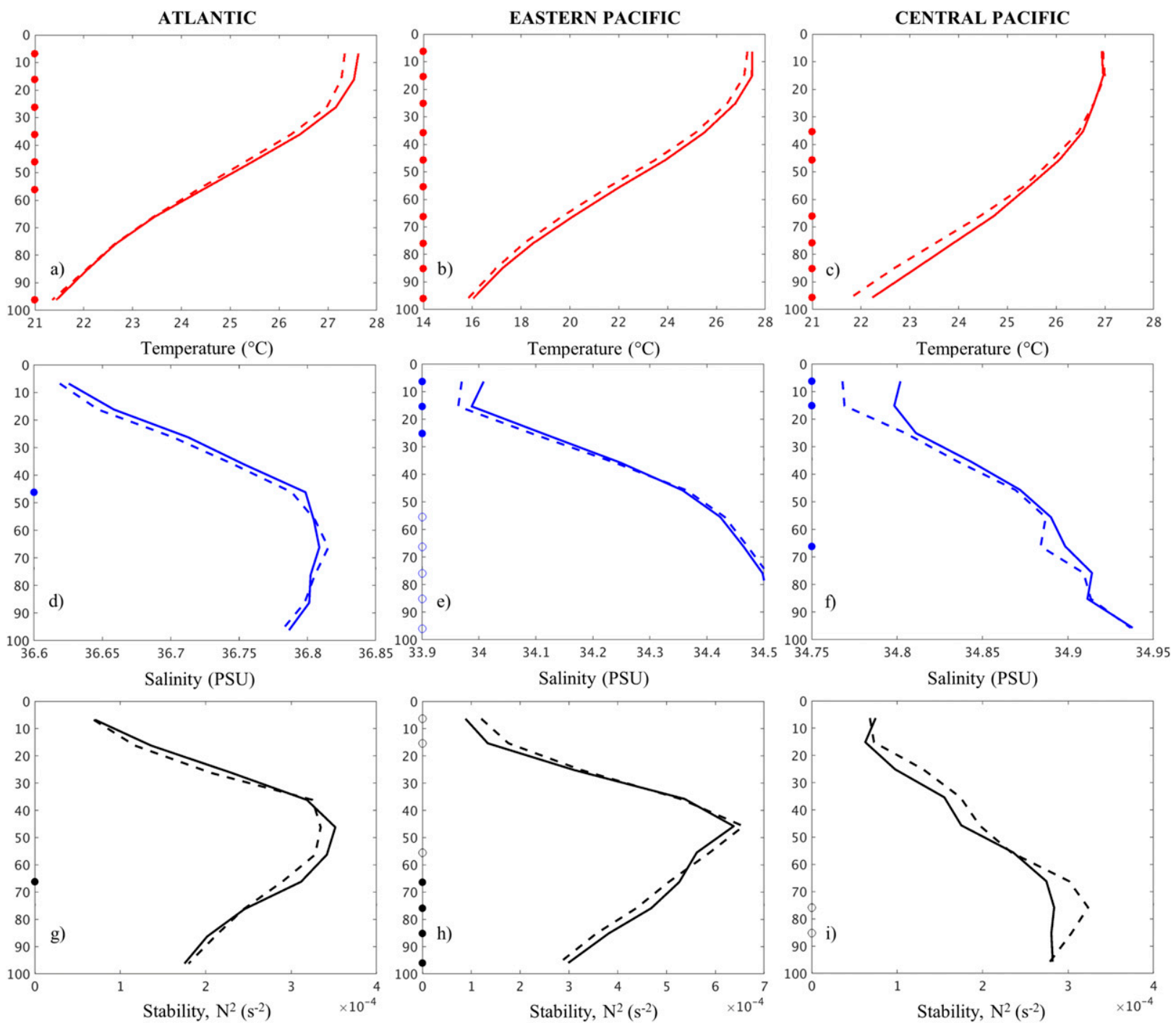

FIG. 5. Argo float composites showing vertical profiles of (a)-(c) temperature, (d)-(f) salinity, and (g)-(i) stability for pre-TC (solid line) and post-TC (dashed line) ocean states in the (left) Atlantic, (center) eastern Pacific, and (right) central Pacific TC basins. Depths are binned every $10 \mathrm{~m}$ from the surface to $100 \mathrm{~m}$. Positive (unfilled circles) and negative (filled circles) statistically significant changes at $95 \%$ confidence for a particular level are shown along the $y$ axis.

salinity profiles. The near-surface salinity change is largely responsible for increased stratification in the upper $20 \mathrm{~m}$ and the temperature profile impacts stratification from 20 to $100 \mathrm{~m}$ (Fig. 5).

\section{d. Physical relationships between TCs and the barrier layer}

Argo TC pairs for the Atlantic basin are subset to investigate relationships between barrier layer development and TC physical parameters: TC intensity, TC translation speed, radial distance from TC center, and time after TC passage. First, barrier layer characteristics are positively correlated with TC intensity. TC wind forcing enhances upper-ocean turbulent mixing and deepens the ITLD, thereby increasing BLT and BLPE values (Fig. 6). Second, TC translation speed determines the length of time that coupled air-sea interactions occur. The slowest translation speed bin $\left(<2 \mathrm{~m} \mathrm{~s}^{-1}\right)$ has minimal changes in barrier layer characteristics. Slowmoving storms tend to homogenize the temperature and salinity profiles, as a longer period of turbulent mixing erodes stratified layers. In addition, a longer period of oceanic upwelling causes the ITLD to shoal, counteracting ITLD deepening due to turbulent mixing. Mediumand fast-moving TCs all show increases in barrier layer metrics. Third, the radial distance from the TC center 

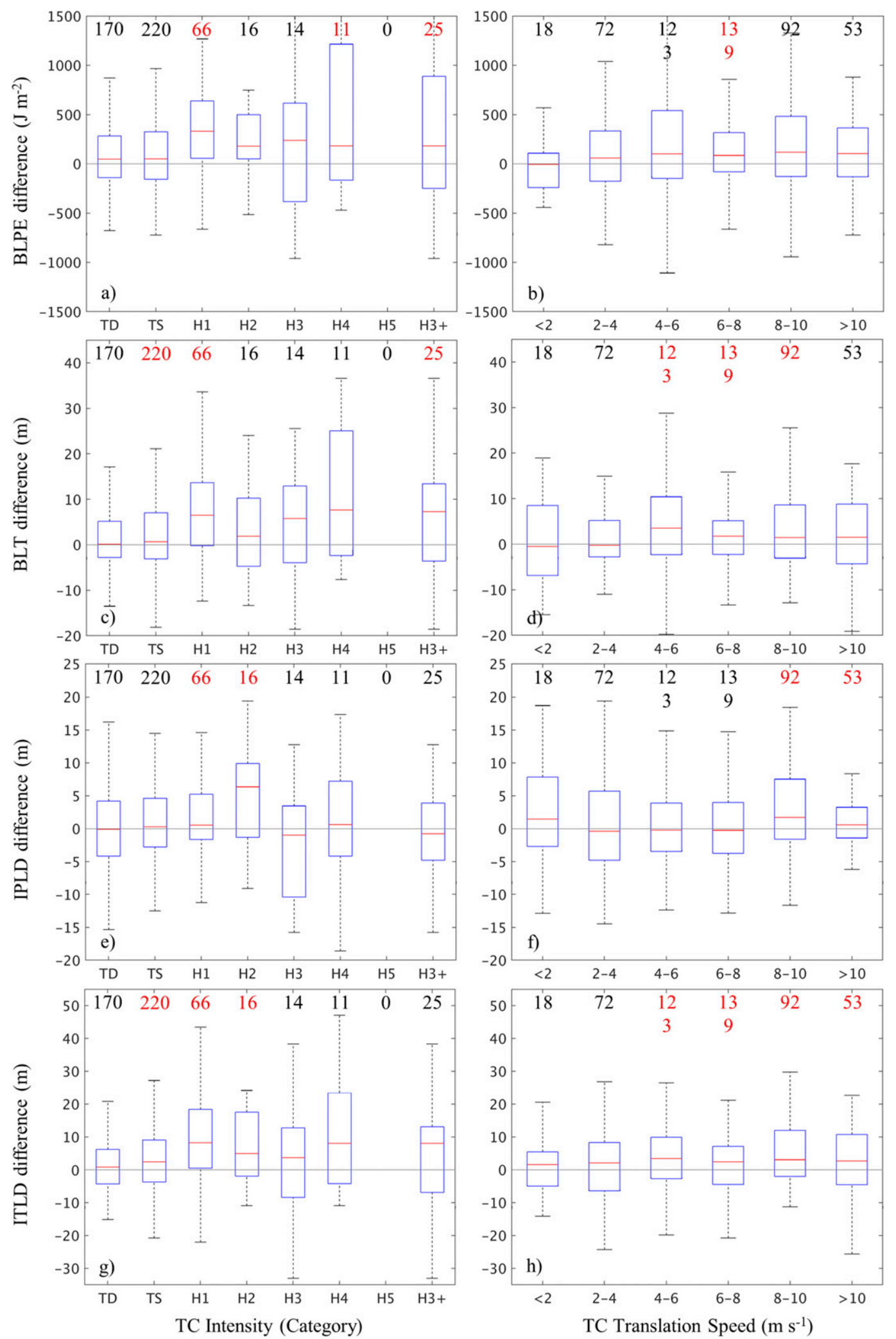

FIG. 6. Differences in (a),(b) BLPE, (c),(d) BLT, (e),(f) IPLD, and (g),(h) ITLD between post-TC and pre-TC Argo float pairs in the Atlantic TC basin. Argo data are subset based on (left) Saffir-Simpson scale TC intensity and (right) TC translation speed. The number of samples is listed above each bin, with red indicating a statistically significant difference from zero at the $95 \%$ confidence interval. 
determines the relative influence of upwelling and wind forcing on ITLD changes. The inner most radial distance bin $(<50 \mathrm{~km})$ encompasses the radius of maximum winds, and is therefore an area of enhanced upwelling and the strongest wind forcing. There is no significant change to the barrier layer within $50 \mathrm{~km}$, as upwelling and turbulent mixing presumably have opposing effects on ITLD. However, the other radial bins have increased ITLD, where TC-forced turbulent mixing is the dominant process (Fig. 7). Because there is little change in IPLD across all radial bins, the increased ITLD from distances greater than $50 \mathrm{~km}$ results in BLT and BLPE increases. Finally, the amount of time between TC passage and Argo profile measurements determines how much of the TC-forced signal is observed. After the forced stage of the TC, advective and dispersive processes begin to erode the salinity minima near the surface. IPLD and ITLD changes begin to stabilize. The largest increases in barrier layer metrics occur between 1 and 3 days after TC passage (Fig. 7), while ITLD and BLPE increase for all ten 1-day bins.

\section{Physical mechanisms related to barrier layer evolution}

The three-dimensional ocean temperature and salinity structure effect barrier layer evolution during the forced stage of a TC and directly after. There are strong statistical relationships between Argo pre-TC temperature and salinity profiles and barrier layer evolution (Tables 4 and 5). Generally, the presence of a strong, preexisting barrier layer in Argo float profiles results in less mixed layer cooling, consistent with previous literature (Wang et al. 2011; Balaguru et al. 2012; Chi et al. 2014). Ocean turbulent mixing acts to homogenize the temperature and salinity profiles, resulting in partially or fully eroded barrier layers. For these cases, large reductions in barrier layer metrics are observed in the post-TC Argo profiles. Contrarily, Argo profiles with thin, weak barrier layers have minimal salinity stratification and/or shallow ITLDs that result in a stronger mixed layer cooling response to TCs. These cases often result in substantial ITLD deepening in the post-TC profiles, which leads to barrier layer formation or enhancement. To explicate these relationships, quartiles of pre-TC ITLD and near-surface salinity are used to examine TC-ocean interaction across different ocean states.

\section{a. $\triangle I T L D$ mechanism}

The barrier layer response is highly dependent upon pre-TC ITLD values (Table 4). The upper $75 \%$ quartile (q75) mean of ITLD in the Atlantic, eastern Pacific, and central Pacific basins is 59.2, 47.2, and $81.3 \mathrm{~m}$, respectively. These profiles usually have strong barrier layers due to their deep ITLDs. The TC-forced response in these Argo profiles results in a statistically significant reduction in near-surface cooling $(\sim 6 \mathrm{~m})$ in the Atlantic and eastern Pacific basins. In the Atlantic, surface cooling is reduced by half $\left(-0.18^{\circ} \mathrm{C}\right)$ compared to the median 50th quantile average $\left(-0.35^{\circ} \mathrm{C}\right)$. In most of these cases, turbulent mixing does not extend down to the ITLD, and coupled TC-ocean interaction is dampened. The negative feedback mechanism between SST cooling and TC intensity is weakened for deep ITLD cases.

Since pre-TC Argo profiles with deep ITLDs generally have thick barrier layers, the TC-induced response is barrier layer erosion. The q75 ITLDs shoal by $-1.2,-7.8$, and $-11.1 \mathrm{~m}$ in the Atlantic, eastern Pacific, and central Pacific basins (Table 4). Upwelling is likely the dominant mechanism for raising the post-TC ITLDs. The corresponding change in BLPE is a reduction of -30.2 , -337.5 , and $-740.3 \mathrm{~J} \mathrm{~m}^{-2}$, respectively. These changes in barrier layer metrics are large and statistically significant at the 95th percentile.

The lower $25 \%$ quartile (q25) means in pre-TC ITLDs are 21.3, 18.1, and $31.9 \mathrm{~m}$ in the Atlantic, eastern Pacific, and central Pacific basins. Compared to the q75 ITLD mean, the q25 ITLD mean is about $30-40 \mathrm{~m}$ shallower. There are competing effects on TC-induced cooling when the thermocline is shallow. Generally, the vertical gradient of temperature increases upper-ocean stratification, which constrains mixed layer cooling. However, the thermocline is also closer to the surface, so sufficiently strong TC wind forcing may overcome the enhanced stratification. Analysis of the post-TC Argo float temperature profiles shows that the later process is dominant. The cooling response in q25 ITLD profiles is several times stronger than the q75 ITLD response. The near-surface cooling observed in q25 ITLD profiles is $-0.39^{\circ},-0.53^{\circ}$, and $-0.11^{\circ} \mathrm{C}$ for the Atlantic, eastern Pacific, and central Pacific basins. In addition, turbulent mixing in q25 profiles is able to penetrate the thermocline and deepen the ITLDs by $+6.5,+6.0$, and $+3.1 \mathrm{~m}$, respectively. As the ITLD deepens, there is a corresponding increase in the barrier layer as well.

\section{b. Near-surface freshening mechanism}

Near-surface salinity stratification can also enhance the barrier layer and confine turbulent mixing closer to the surface. This effect is most noticeably present in the Atlantic basin for pre-TC Argo floats that have near-surface salinity values in the lower $25 \%$ quartile (fresher). In response to TC forcing, higher saline water from depth is mixed toward the surface, causing an increase of +0.14 PSU. The temperature response 

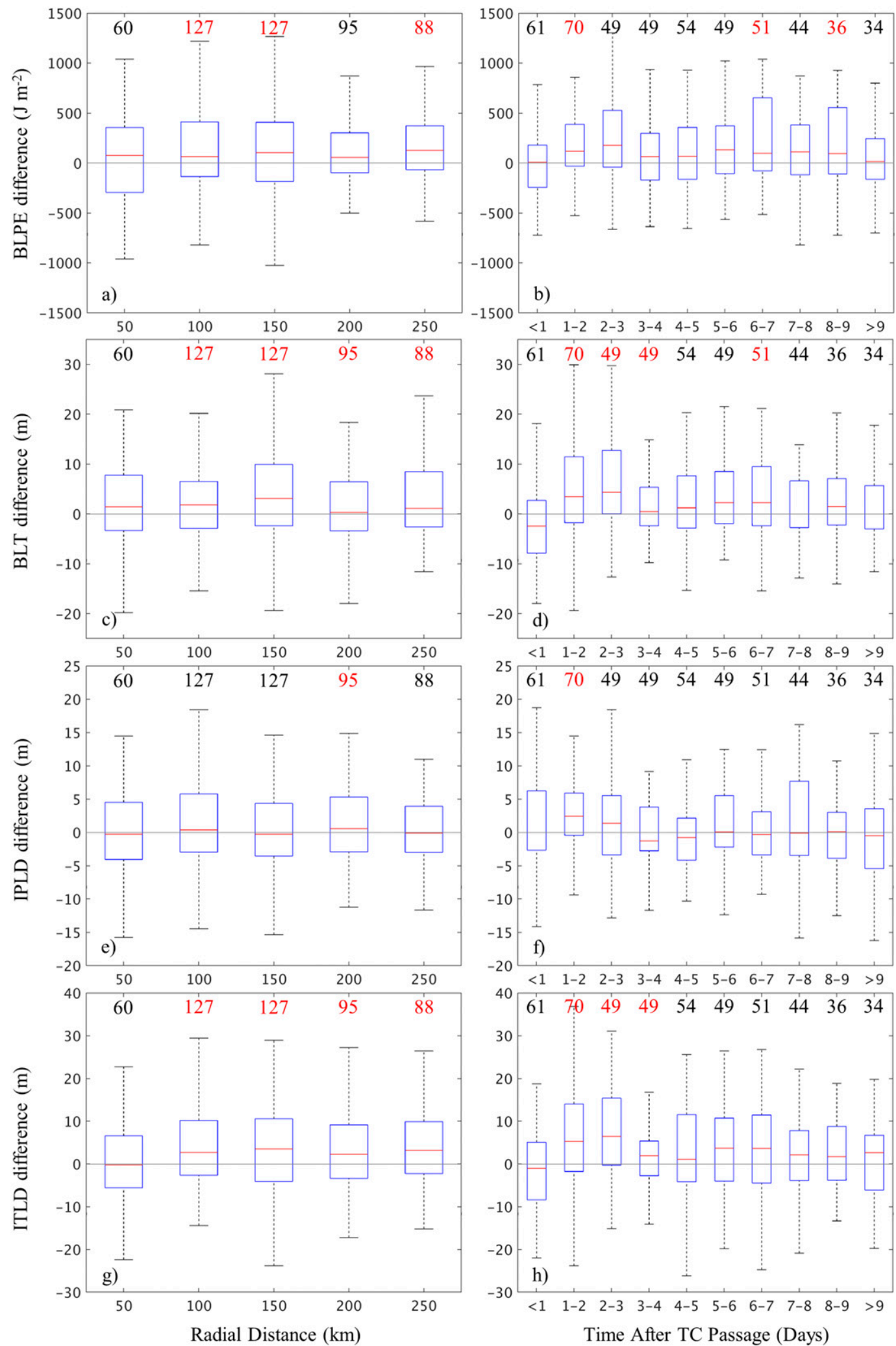

FIG. 7. As in Fig. 6, but Argo data are subset based on (left) radial distance from TC center and (right) time after TC passage. 
TABLE 4. Argo pre-TC values of ITLD (mean of lower 25th and upper 75th quartiles) and corresponding changes in barrier layer characteristics. Bolded values indicate statistical significance at the 95th percentile compared to 50th inner quantile means. Inner 50th quantile means: Atlantic $\Delta \mathrm{SSS}=-0.01, \Delta \mathrm{SST}=-0.35, \Delta \mathrm{ITLD}=+3.86, \Delta \mathrm{BLPE}=+156.7$; eastern Pacific $\Delta \mathrm{SSS}=-0.02, \Delta \mathrm{SST}=-0.09$, $\Delta \mathrm{ITLD}=+0.34, \Delta \mathrm{BLPE}=+27.4$; and central Pacific $\Delta \mathrm{SSS}=-0.03, \Delta \mathrm{SST}=+0.06, \Delta \mathrm{ITLD}=-0.24, \Delta \mathrm{BLPE}=+84.8$.

\begin{tabular}{|c|c|c|c|c|c|c|c|c|c|c|}
\hline \multirow[b]{2}{*}{$\mathrm{TC}$ basin } & \multicolumn{5}{|c|}{ Lower $25 \%$ quartile } & \multicolumn{5}{|c|}{ Upper $75 \%$ quartile } \\
\hline & $\begin{array}{l}\text { ITLD } \\
(\mathrm{m})\end{array}$ & $\begin{array}{l}\Delta S S S \\
(\mathrm{PSU})\end{array}$ & $\begin{array}{c}\Delta \mathrm{SST} \\
\left({ }^{\circ} \mathrm{C}\right)\end{array}$ & $\begin{array}{c}\Delta \text { ITLD } \\
(\mathrm{m})\end{array}$ & $\begin{array}{l}\triangle B L P E \\
\left(\mathrm{~J} \mathrm{~m}^{-2}\right)\end{array}$ & $\begin{array}{l}\text { ITLD } \\
(\mathrm{m})\end{array}$ & $\begin{array}{l}\Delta \mathrm{SSS} \\
(\mathrm{PSU})\end{array}$ & $\begin{array}{c}\Delta \mathrm{SST} \\
\left({ }^{\circ} \mathrm{C}\right)\end{array}$ & $\begin{array}{l}\Delta \mathrm{ITLD} \\
(\mathrm{m})\end{array}$ & $\begin{array}{l}\triangle \mathrm{BLPE} \\
\left(\mathrm{J} \mathrm{m}^{-2}\right)\end{array}$ \\
\hline Atlantic & 21.3 & +0.01 & -0.39 & +6.5 & +166.1 & 59.2 & -0.00 & -0.18 & -1.2 & -30.2 \\
\hline $\begin{array}{l}\text { Eastern } \\
\text { Pacific }\end{array}$ & 18.1 & -0.03 & $-\mathbf{0 . 5 3}$ & +6.0 & +166.1 & 47.2 & -0.04 & +0.00 & -7.8 & -337.5 \\
\hline $\begin{array}{l}\text { Central } \\
\text { Pacific }\end{array}$ & 31.9 & -0.08 & $-\mathbf{0 . 1 1}$ & +3.1 & +114.4 & 81.3 & -0.02 & +0.09 & -11.1 & -740.3 \\
\hline
\end{tabular}

is muted, with a near-surface cooling of $-0.22^{\circ} \mathrm{C}$ in q 25 salinity profiles compared to $-0.39^{\circ} \mathrm{C}$ for the 50th quantile mean (Table 5). This is consistent with less turbulent mixing throughout the ITLD, since the $\triangle \mathrm{ITLD}$ is only $+0.46 \mathrm{~m}$ compared to $+4.26 \mathrm{~m}$ for the 50th quantile mean. Despite a slight increase in ITLD, the BLPE decrease in the post-TC Argo profiles is $-147.1 \mathrm{~J} \mathrm{~m}^{-2}$ as salinity stratification is eroded. The central Pacific response is qualitatively similar to the Atlantic, but there is only a statistical significance in $\triangle$ ITLD. Interestingly, the eastern Pacific response for profiles with a fresh surface layer is more ambiguous. The $\Delta \mathrm{SST}$ is $-0.41^{\circ} \mathrm{C}$, which is more than twice the cooling $\left(-0.19^{\circ} \mathrm{C}\right)$ seen in the 50th quantile mean. Therefore, a fresh near-surface salinity signal may not correlate with increased stratification for the eastern Pacific basin. Temperature stratification may play a larger role in barrier layer response. Overall, there is a reduction in BLPE for all basins as preexisting salinity stratification is eroded.

The upper $75 \%$ quantile in near-surface salinity represents profiles with minimal salinity stratification. There is more near-surface cooling in the q75 salinity Argo profiles in the Atlantic and central Pacific. The mixed layer cooling is coherent with a deepening of the $\Delta$ ITLD in the Atlantic $(4.09 \mathrm{~m})$ and central Pacific
$(+3.00 \mathrm{~m})$ basins (Table 5). The response in $\triangle \mathrm{BLPE}$ is also consistent, with an increase of +218.8 and $+183.9 \mathrm{~J} \mathrm{~m}^{-2}$, respectively. A slight freshening of the near-surface and a deepening of ITLD enhances the barrier layer in the q75 salinity profiles.

Moreover, important relationships exist between near-surface salinity change and different TC characteristics (Fig. 8). Generally, slower-moving TCs $\left(0-6 \mathrm{~m} \mathrm{~s}^{-1}\right)$ are more likely to have a salinity decrease within the upper $10 \mathrm{~m}$ of the ocean (Figs. 8d-f). While slow-moving TCs can accumulate higher precipitation totals over the ocean, a longer duration of TC wind forcing enhances turbulent mixing and can erode freshwater layers. Based on the Argo float data of slowmoving TCs, more profiles experience surface freshening from precipitation than surface salinification from evaporation and vertical entrainment. The radial location of Argo float measurements within TCs also shows a strong relationship with surface salinity change. For Argo samples within the inner $\sim 150 \mathrm{~km}$ closest to the TC center, freshening is prevalent (Figs. $8 \mathrm{~g}-\mathrm{i}$ ). Only a few of the $25-\mathrm{km}$ bins have salinity increases. Once again, competing processes vary strongly with radial extent from the TC center. Heavy precipitation is confined to the eyewall region and surrounding rainbands. The precipitation-driven freshwater flux into the ocean

TABLE 5. Argo pre-TC values of near-surface salinity (mean of lower 25th and upper 75th quartiles) and corresponding changes in barrier layer characteristics. Bolded values indicate statistical significance at the 95th percentile compared to 50th inner quantile means. Inner 50th quantile means: Atlantic $\Delta \mathrm{SSS}=-0.03, \Delta \mathrm{SST}=-0.39, \Delta \mathrm{ITLD}=+4.26, \Delta \mathrm{BLPE}=+189.1 ;$ eastern Pacific $\Delta \mathrm{SSS}=-0.05$, $\Delta \mathrm{SST}=-0.19, \Delta \mathrm{ITLD}=+0.37, \Delta \mathrm{BLPE}=+5.5 ;$ central Pacific $\Delta \mathrm{SSS}=-0.03, \Delta \mathrm{SST}=+0.05, \Delta \mathrm{ITLD}=-2.82, \Delta \mathrm{BLPE}=-117.8$.

\begin{tabular}{|c|c|c|c|c|c|c|c|c|c|c|}
\hline \multirow[b]{2}{*}{ TC basin } & \multicolumn{5}{|c|}{ Lower $25 \%$ quartile } & \multicolumn{5}{|c|}{ Upper $75 \%$ quartile } \\
\hline & $\begin{array}{c}\text { Salinity } \\
\text { (PSU) }\end{array}$ & $\begin{array}{c}\Delta \text { SSS } \\
\text { (PSU) }\end{array}$ & $\begin{array}{c}\Delta \mathrm{SST} \\
\left({ }^{\circ} \mathrm{C}\right)\end{array}$ & $\begin{array}{c}\Delta \text { ITLD } \\
(\mathrm{m})\end{array}$ & $\begin{array}{l}\Delta \mathrm{BLPE} \\
\left(\mathrm{J} \mathrm{m}^{-2}\right)\end{array}$ & $\begin{array}{c}\text { Salinity } \\
\text { (PSU) }\end{array}$ & $\begin{array}{c}\Delta \mathrm{SSS} \\
(\mathrm{PSU})\end{array}$ & $\begin{array}{c}\Delta \mathrm{SST} \\
\left({ }^{\circ} \mathrm{C}\right)\end{array}$ & $\begin{array}{c}\Delta \text { ITLD } \\
(\mathrm{m})\end{array}$ & $\begin{array}{l}\Delta \mathrm{BLPE} \\
\left(\mathrm{J} \mathrm{m}^{-2}\right)\end{array}$ \\
\hline Atlantic & 35.4 & +0.14 & -0.22 & +0.46 & -147.1 & 37.3 & -0.06 & -0.25 & +4.09 & +218.8 \\
\hline $\begin{array}{l}\text { Eastern } \\
\text { Pacific }\end{array}$ & 33.4 & +0.04 & -0.41 & -0.72 & -136.7 & 34.7 & -0.06 & +0.09 & -1.12 & +8.8 \\
\hline $\begin{array}{l}\text { Central } \\
\text { Pacific }\end{array}$ & 34.4 & -0.05 & +0.07 & -5.85 & -401.3 & 35.2 & -0.05 & -0.06 & +3.00 & +183.9 \\
\hline
\end{tabular}



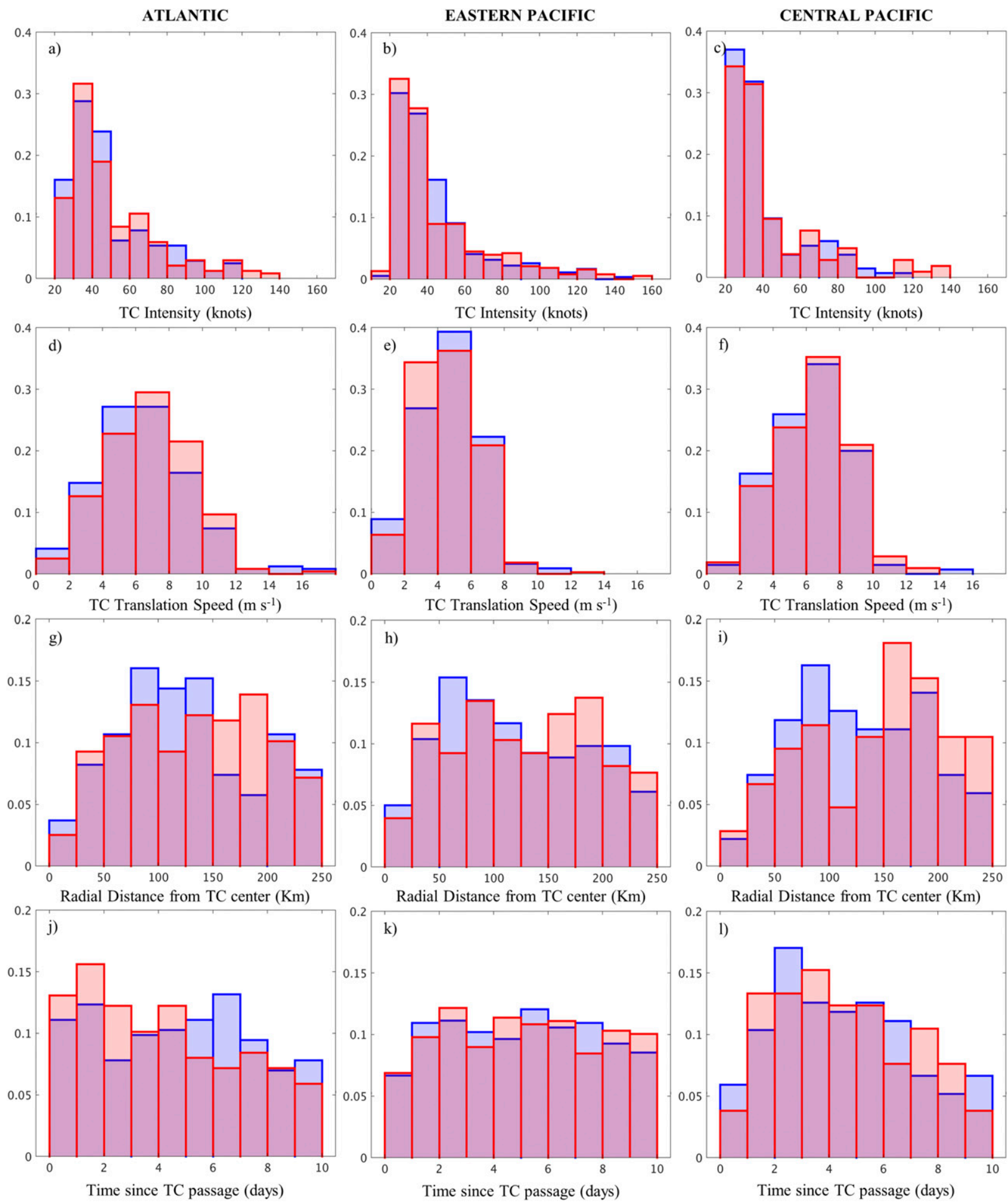

FIG. 8. Normalized histograms of near-surface freshening (blue) and salinification (red) for the (left) Atlantic, (center) eastern Pacific, and (right) central Pacific basins. Distributions are subset based on (a)-(c) TC intensity, (d)-(f) TC translation speed, (g)-(i) radial distance, and (j)-(l) time after TC passage. 
produces net freshening within $150 \mathrm{~km}$ of the TC center. From 150 to $250 \mathrm{~km}$, precipitation is substantially reduced (Lonfat et al. 2004), and ocean mixing can lead to near-surface salinity increases due to entrainment. There are no consistent trends in near-surface salinity changes in response to TC intensity (Figs. $8 \mathrm{a}-\mathrm{c}$ ) or the Argo sampling time after TC passage (Figs. $8 \mathrm{j}-1$ ).

Freshening occurs more frequently than salinification near TC centers (Figs. 8g-i), which can regulate the amount of ocean mixing and cooling under TCs (Fig. 9). This result is particularly evident in the eastern Pacific basin as freshening within $150 \mathrm{~km}$ of TC centers occurs $61.7 \%$ of the time and every $25-\mathrm{km}$ bin within $150 \mathrm{~km}$ has more cases of freshening than salinification (Fig. 9b). The Atlantic basin shows a similar signal, albeit weaker, as higher frequencies of freshening occur in the 100 $150-\mathrm{km}$ bins that may be linked to enhanced precipitation within TC rainbands (Fig. 9a). Unfortunately, the central Pacific lacks sufficient data (23 samples within inner $50 \mathrm{~km}$ ) to form any clear deductions on the dominant salinity response near TC centers. However, a clear preference for freshening occurs from 50 to $150 \mathrm{~km}$ where there is more data availability (Fig. 9c). As a result, all three TC basins show a consistent pattern of reduced near-surface salinity within the inner radial bins. The median magnitude of salinity change does not show a strong radial dependence, however. Most Argo float profiles have salinity responses within $\pm 0.2 \mathrm{PSU}$ from their pre-TC value (Figs. 9a-c). In addition, the salinity response within the inner $25-\mathrm{km}$ bin is positively correlated to TC minimum central pressure and is statistically significant at $95 \%$ confidence for both the Atlantic $(r=0.71)$ and eastern Pacific $(r=0.39)$ basins. Stronger TCs have more organized, deep convection near the center, which enhances upper-ocean freshening from precipitation.

The feedback between precipitation-driven freshening acts to increase upper-ocean stratification and reduce SST cooling under TCs. Therefore, these air-sea interactions have important implications for TC thermodynamics. The strongest near-surface cooling occurs close to the TC center $(<50 \mathrm{~km})$ in most cases, with less cooling observed in radial bins at farther distances (Figs. 9d-f). Interestingly, Argo float profiles that experience freshening near the TC center, have less near-surface cooling when compared to profiles that experience salinification. This relationship between freshening and a dampened cooling response is strongest in the eastern Pacific and is apparent in the Atlantic basin. The most obvious example is the near-surface temperature change in the inner 25-km bin for the eastern Pacific basin (Fig. 9e). The median temperature response between Argo profiles with freshening $\left(-0.09^{\circ} \mathrm{C}\right)$ versus salinification $\left(-1.26^{\circ} \mathrm{C}\right)$ are statistically different at $>99 \%$ confidence based on a Wilcoxon rank sum test. Most of the other radial bins lack statistical significance due to limited sample sizes and other physical controls that determine the SST cold wake magnitude (i.e., TC intensity, size, speed).

Barrier layer characteristics, such as ITLD and BLPE, also exhibit strong relationships with near-surface salinity change. In both Pacific basins, the ITLD shoals more in profiles with decreased salinity compared to those with increased salinity in the 0-25-, 25-50-, and 50-75-km radial bins (Figs. 9h,i). The opposite response is observed in the Atlantic basin, where the ITLD preferentially deepens in response to TC passage (Fig. 9g). BLPE increases are generally larger for the freshening cases compared to salinification cases across most radial bins in the Atlantic basin (Fig. 9j). The eastern Pacific also has barrier layer enhancement for bins within the inner $125-\mathrm{km}$ radius (Fig. 9k).

These results indicate that near-surface freshening is the dominant response close to TC centers. Based upon Argo data subsets for freshening cases compared to salinification cases, upper-ocean cooling and barrier layer characteristics are sensitive to salinity changes. Surface freshening tends to suppress the SST cooling response, making conditions more thermodynamically favorable for TCs. An analysis of TC intensification rates calculated from HURDAT2 show no statistically significant differences between freshening and salinification cases, however. This result is expected since there are a limited number of observations within the inner $50-\mathrm{km}$ radius and many other oceanic and atmospheric factors contribute to TC intensity change. Therefore, the extent to which this mechanism affects TC intensification remains an open and important question in the context of coupled air-sea interactions.

\section{Discussion}

The Argo float network provides a novel way of determining the average, basin-specific response of temperature and salinity to TC passage. Inclusion of the salinity response in this analysis provides insights into upper-ocean stratification that are often missed when only considering the temperature response. While a well-mixed, homogenous temperature profile decreases ocean stratification, the presence of a fresh near-surface layer increases upper-ocean stratification. In this sense, the vertical profiles of temperature and salinity can have the opposite effect on stratification, and both are important controls on TC-forced turbulent mixing and ocean mixed layer cooling. Therefore, the negative feedback mechanism between SST cooling and TC intensity may be overestimated without including salinity 
ATLANTIC
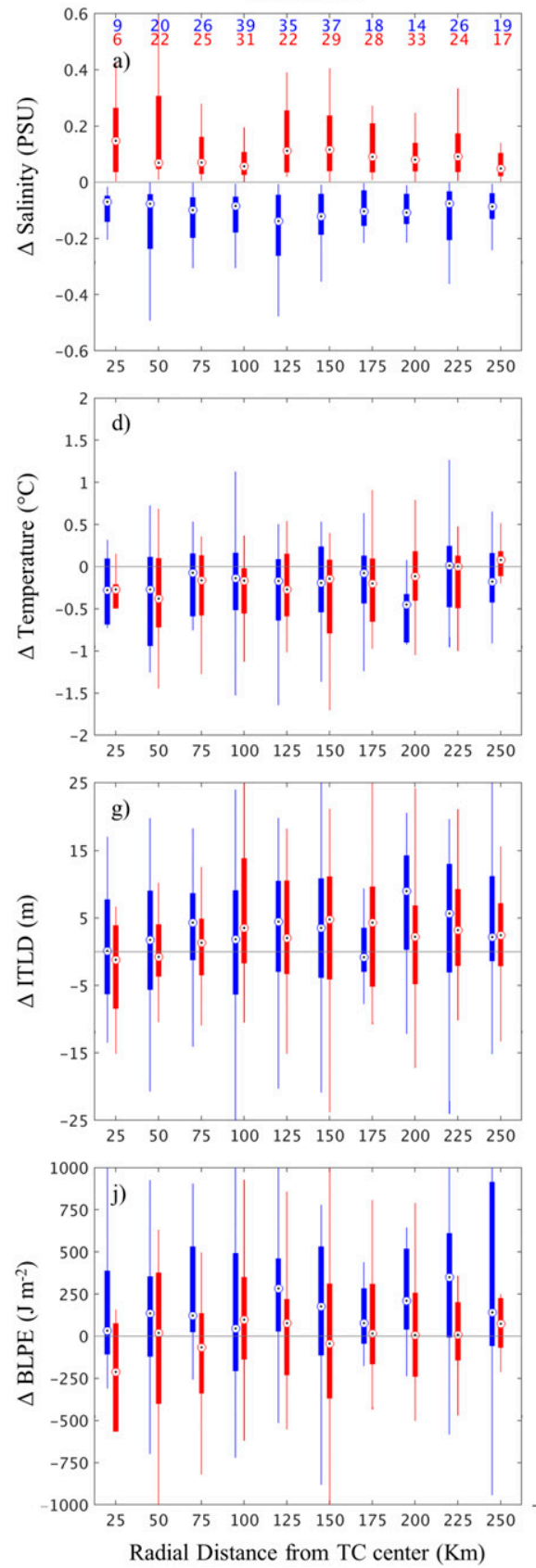

EASTERN PACIFIC
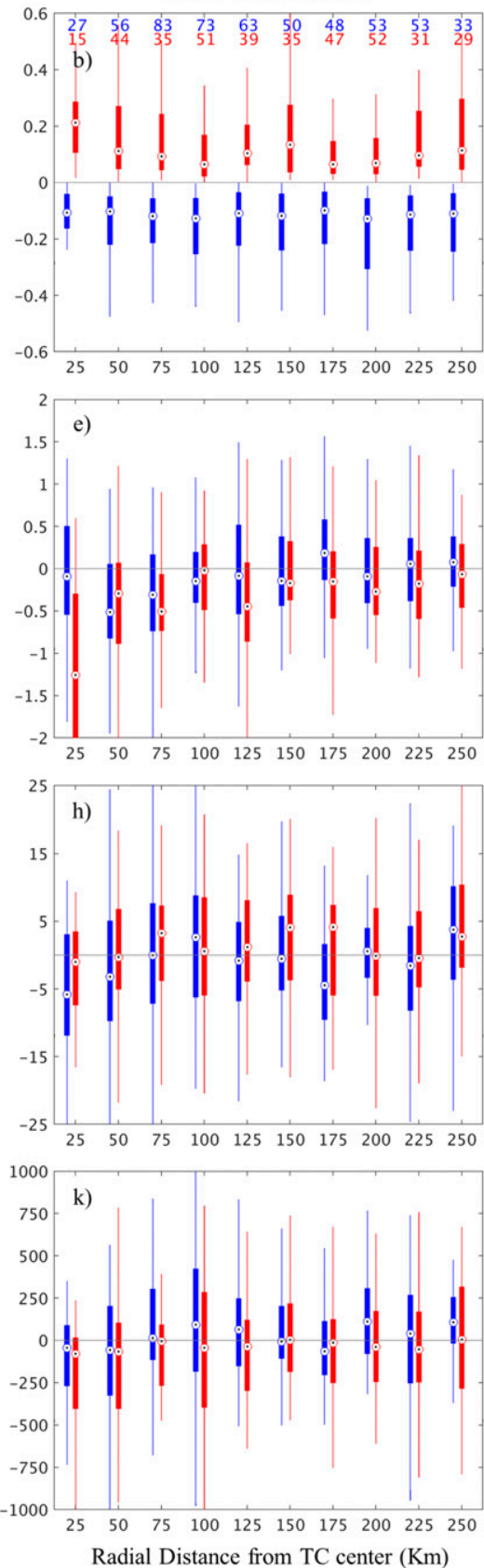

CENTRAL PACIFIC
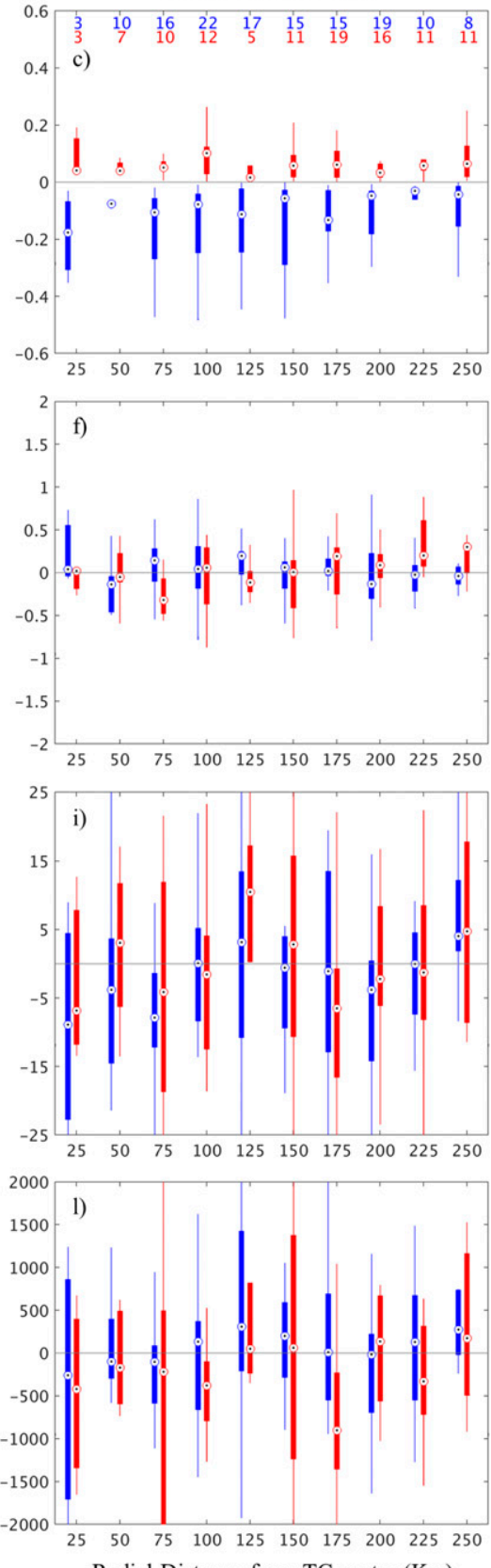

FIG. 9. Boxplots of TC-induced changes in barrier layer characteristics as a function of radial distance from TC center for the (left) Atlantic, (center) eastern Pacific, and (right) central Pacific TC basins. Argo float data are parsed by their near-surface salinity responses, where freshening (blue) and salinification (red) are plotted separately. Changes in (a)-(c) salinity (PSU), (d)-(f) temperature $\left({ }^{\circ} \mathrm{C}\right)$, (g)-(i) ITLD (m), and (j)-(l) BLPE $\left(\mathrm{J} \mathrm{m}^{-2}\right)$ all show radial dependencies.

effects. To reveal the dominant physical mechanisms that contribute to barrier layer development within TCs, coupled atmosphere-ocean model studies with a mixed layer salinity budget are needed (Cronin and McPhaden 2002), along with collocated observations for model validation.
The Atlantic, eastern Pacific, and central Pacific tropical ocean basins all display mixed layer cooling and freshening after TC passage. However, the vertical profile structures of temperature and salinity behave differently in the three basins. For example, the Atlantic basin shows increases in BLT and BLPE, which are driven by ITLD deepening. 
Conversely, the eastern Pacific and central Pacific basins have reduced ITLDs, but a more pronounced freshening in the upper $30 \mathrm{~m}$, which contributes to barrier layer development. While it is likely that large freshwater fluxes due to precipitation are responsible for the near-surface salinity reduction, other factors such as vertical and horizontal advection may play additional roles.

Acknowledgments. This work was funded by the National Aeronautics and Space Administration (Grant NNX15AD45G) and the National Oceanic and Atmospheric Administration (Grant NA11OAR4320199). Argo float data were collected and made freely available by the International Argo Program and the national programs that contribute to it (http://www.argo.ucsd.edu and http:// argo.jcommops.org). The Argo Program is part of the Global Ocean Observing System.

\section{REFERENCES}

Argo, 2000: Argo float data and metadata from Global Data Assembly Centre (Argo GDAC). SEANOE, accessed 18 November 2015, https://doi.org/10.17882/42182.

Balaguru, K., P. Chang, R. Saravanan, L. R. Leung, Z. Xu, M. Li, and J.-S. Hsieh, 2012: Ocean barrier layers' effect on tropical cyclone intensification. Proc. Natl. Acad. Sci. USA, 109, 14343-14347, https://doi.org/10.1073/pnas.1201364109.

_, S. Taraphdar, L. R. Leung, G. R. Foltz, and J. A. Knaff, 2014: Cyclone-cyclone interactions through the ocean pathway. Geophys. Res. Lett., 41, 6855-6862, https://doi.org/10.1002/ 2014 GL061489.

Baranowski, D. B., P. J. Flatau, S. Chen, and P. G. Black, 2014: Upper ocean response to two collocated typhoons. Ocean Sci., 10, 559-570, https://doi.org/10.5194/os-10-559-2014.

Bender, M. A., I. Ginis, and Y. Kurihara, 1993: Numerical simulations of tropical cyclone-ocean interaction with a high-resolution coupled model. J. Geophys. Res., 98, 23245-23263, https://doi.org/ 10.1029/93JD02370.

Brainerd, K. E., and M. C. Gregg, 1995: Surface mixed and mixing layer depths. Deep Sea Res., 42, 1521-1543, https://doi.org/ 10.1016/0967-0637(95)00068-H.

Brand, S., 1971: The effects on a tropical cyclone of cooler surface waters due to upwelling and mixing produced by a prior tropical cyclone. J. Appl. Meteor., 10, 865-874, https://doi.org/ 10.1175/1520-0450(1971)010<0865:TEOATC >2.0.CO;2.

Carval, T., and Coauthors, 2011: Argo user's manual V3.2, IFREMER, 124 pp., https://doi.org/10.13155/29825.

Chang, S. W., and R. A. Anthes, 1978: Numerical simulations of the ocean's nonlinear, baroclinic response to translating hurricanes. J. Phys. Oceanogr., 8, 468-480, https://doi.org/10.1175/ 1520-0485(1978)008<0468:NSOTON>2.0.CO;2.

Chi, N.-H., R.-C. Lien, E. A. D'Asaro, and B. B. Ma, 2014: The surface mixed layer heat budget from mooring observations in the central Indian Ocean during Madden-Julian Oscillation events. J. Geophys. Res. Oceans, 119, 4638-4652, https://doi.org/ 10.1002/2014JC010192.

Cione, J. J., and E. W. Uhlhorn, 2003: Sea surface temperature variability in hurricanes: Implications with respect to intensity change. Mon. Wea. Rev., 131, 1783-1796, https://doi.org/ 10.1175//2562.1.

Cronin, M. F., and M. J. McPhaden, 2002: Barrier layer formation during westerly wind bursts. J. Geophys. Res., 107, 8020, https://doi.org/10.1029/2001JC001171.

Dare, R. A., and J. L. McBride, 2011: Sea surface temperature response to tropical cyclones. Mon. Wea. Rev., 139, 3798-3808, https://doi.org/10.1175/MWR-D-10-05019.1.

D'Asaro, E. A., T. B. Sanford, P. P. Niiler, and E. J. Terrill, 2007: Cold wake of Hurricane Frances. Geophys. Res. Lett., 34, L15609, https://doi.org/10.1029/2007GL030160.

de Boyer Montegut, C., G. Madec, A. S. Fischer, A. Lazar, and D. Iudicone, 2004: Mixed layer depth over the global ocean: An examination of profile data and a profile-based climatology. J. Geophys. Res., 109, C12003, https://doi.org/ 10.1029/2004JC002378.

Domingues, R., and Coauthors, 2015: Upper ocean response to Hurricane Gonzalo (2014): Salinity effects revealed by targeted and sustained underwater glider observations. Geophys. Res. Lett., 42, 7131-7138, https://doi.org/10.1002/2015GL065378.

Elsberry, R. L., T. S. Fraim, and R. N. Trapnell Jr., 1976: A mixed layer model of the oceanic thermal response to hurricanes. J. Geophys. Res., 81, 1153-1162, https://doi.org/ 10.1029/JC081i006p01153.

Enfield, D. B., and D. A. Mayer, 1997: Tropical Atlantic sea surface temperature variability and its relation to El Niño-Southern Oscillation. J. Geophys. Res., 102, 929-945, https://doi.org/ 10.1029/96JC03296.

Fisher, E. L., 1958: Hurricanes and the sea-surface temperature field. J. Meteor., 15, 328-333, https://doi.org/10.1175/ 1520-0469(1958)015<0328:HATSST > 2.0.CO;2.

Foltz, G. R., and M. J. McPhaden, 2009: Impact of barrier layer thickness on SST in the central tropical North Atlantic. J. Climate, 22, 285-299, https://doi.org/10.1175/2008JCLI2308.1.

—, S. A. Grodsky, J. A. Carton, and M. J. McPhaden, 2003: Seasonal mixed layer heat budget of the tropical Atlantic Ocean. J. Geophys. Res., 108, 3146, https://doi.org/10.1029/2002JC001584.

_ mixed layer heat balance of the southwestern tropical Indian Ocean. J. Climate, 23, 947-965, https://doi.org/10.1175/ 2009JCLI3268.1.

Fu, H. L., X. Wang, P. C. Chu, X. Zhang, G. Han, and W. Li, 2014: Tropical cyclone footprint in the ocean mixed layer observed by Argo in the northwest Pacific. J. Geophys. Res. Oceans, 119, 8078-8092, https://doi.org/10.1002/2014JC010316.

Jacob, S. D., and C. J. Koblinsky, 2007: Effects of precipitation on the upper-ocean response to a hurricane. Mon. Wea. Rev., 135, 2207-2224, https://doi.org/10.1175/MWR3366.1.

Jaimes, B., and L. K. Shay, 2010: Near-inertial wave wake of Hurricanes Katrina and Rita over mesoscale oceanic eddies. J. Phys. Oceanogr., 40, 1320-1337, https://doi.org/10.1175/2010JPO4309.1.

Jourdain, N. C., M. Lengaigne, J. Vialard, G. Madec, C. E. Menkes, E. M. Vincent, S. Jullien, and B. Barnier, 2013: Observationbased estimates of surface cooling inhibition by heavy rainfall under tropical cyclones. J. Phys. Oceanogr., 43, 205-221, https://doi.org/10.1175/JPO-D-12-085.1.

Leipper, D. F., 1967: Observed ocean conditions and Hurricane Hilda, 1964. J. Atmos. Sci., 24, 182-196, https://doi.org/10.1175/ 1520-0469(1967)024<0182:OOCAHH > 2.0.CO;2.

Lloyd, I. D., and G. A. Vecchi, 2011: Observational evidence for oceanic controls on hurricane intensity. J. Climate, 24, 1138-1153, https://doi.org/10.1175/2010JCLI3763.1. 
Lonfat, M., F. D. Marks Jr., and S. S. Chen, 2004: Precipitation distribution in tropical cyclones using the Tropical Rainfall Measuring Mission (TRMM) Microwave Imager: A global perspective. Mon. Wea. Rev., 132, 1645-1660, https://doi.org/ 10.1175/1520-0493(2004)132<1645:PDITCU>2.0.CO;2.

Morozov, E. G., and M. G. Velarde, 2008: Inertial oscillations as deep ocean response to hurricanes. J. Oceanogr., 64, 495-509, https://doi.org/10.1007/s10872-008-0042-0.

NOAA Climate Prediction Center, 2018: Oceanic Niño Index. Accessed 22 January 2018, http://www.cpc.ncep.noaa.gov/ products/analysis_monitoring/ensostuff/ONI_v5.php.

Park, J., K.-A. Park, K. Kim, and Y.-H. Youn, 2005: Statistical analysis of upper ocean temperature response to typhoons from Argo floats and satellite data. IEEE Int. Geoscience and Remote Sensing Symp., Seoul, South Korea, IEEE, 2564-2567, https://doi.org/10.1109/IGARSS.2005.1525508.

Price, J. F., 1981: Upper ocean response to a hurricane. J. Phys. Oceanogr., 11, 153-175, https://doi.org/10.1175/1520-0485(1981)011<0153: UORTAH $>2.0 . \mathrm{CO} ; 2$.

_ T. B. Sanford, and G. Z. Forristall, 1994: Forced stage response to a moving hurricane. J. Phys. Oceanogr., 24, 233-260, https:// doi.org/10.1175/1520-0485(1994)024<0233:FSRTAM >2.0.CO;2.

Rao, R. R., R. L. Molinari, and J. F. Festa, 1989: Evolution of the climatological near-surface thermal structure of the tropical Indian Ocean: 1. Description of mean monthly mixed layer depth, and sea surface temperature, surface current, and surface meteorological fields. J. Geophys. Res., 94, 10 801-10 815, https://doi.org/10.1029/JC094iC08p10801.

Sanford, T. B., P. G. Black, J. R. Haustein, J. W. Feeney, G. Z. Forristall, and J. F. Price, 1987: Ocean response to a hurricane. Part I: Observations. J. Phys. Oceanogr., 17, 2065-2083, https:// doi.org/10.1175/1520-0485(1987)017<2065:ORTAHP>2.0.CO;2.

, J. F. Price, and J. B. Girton, 2011: Upper-ocean response to hurricane Frances (2004) observed by profiling EM-APEX floats. J. Phys. Oceanogr., 41, 1041-1056, https://doi.org/ 10.1175/2010JPO4313.1.

Schade, L. R., 2000: Tropical cyclone intensity and sea surface temperature. J. Atmos. Sci., 57, 3122-3130, https://doi.org/ 10.1175/1520-0469(2000)057<3122:TCIASS > 2.0.CO;2.

__ and K. A. Emanuel, 1999: The ocean's effect on the intensity of tropical cyclones: Results from a simple coupled atmosphereocean model. J. Atmos. Sci., 56, 642-651, https://doi.org/10.1175/ 1520-0469(1999)056<0642:TOSEOT >2.0.CO;2.

Schneider, N., and P. Müller, 1990: The meridional and seasonal structures of the mixed-layer depth and its diurnal amplitude observed during the Hawaii-to-Tahiti shuttle experiment. J. Phys. Oceanogr., 20, 1395-1404, https://doi.org/10.1175/ 1520-0485(1990)020<1395:TMASSO >2.0.CO;2.

Shay, L. K., G. J. Goni, and P. G. Black, 2000: Effects of a warm oceanic feature on Hurricane Opal. Mon. Wea. Rev., 128 , 1366-1383, https://doi.org/10.1175/1520-0493(2000)128<1366: EOAWOF $>2.0 . \mathrm{CO} ; 2$.

Spall, M. A., R. A. Weller, and P. W. Furey, 2000: Modeling the three-dimensional upper ocean heat budget and subduction rate during the Subduction Experiment. J. Geophys. Res., 105, 26151-26166, https://doi.org/10.1029/2000JC000228.

Sprintall, J., and M. Tomczak, 1992: Evidence of the barrier layer in the surface layer of the tropics. J. Geophys. Res., 97, 73057316, https://doi.org/10.1029/92JC00407.

Suga, T., K. Motoki, Y. Aoki, and A. M. Macdonald, 2004: The North Pacific climatology of winter mixed layer and mode waters. J. Phys. Oceanogr., 34, 3-22, https://doi.org/10.1175/ 1520-0485(2004)034<0003:TNPCOW $>2.0 . \mathrm{CO} ; 2$.

Thompson, R., 1976: Climatological numerical models of the surface mixed layer of the ocean. J. Phys. Oceanogr., 6, 496-503, https:// doi.org/10.1175/1520-0485(1976)006<0496:CNMOTS>2.0.CO;2.

Thomson, R. E., and I. V. Fine, 2003: Estimating mixed layer depth from oceanic profile data. J. Atmos. Oceanic Technol., 20, 319-329, https://doi.org/10.1175/1520-0426(2003)020<0319: EMLDFO $>2.0 . \mathrm{CO} ; 2$.

Wang, C., R. H. Weisberg, and J. I. Virmani, 1999: Western Pacific interannual variability associated with the El Niño-Southern Oscillation. J. Geophys. Res., 104, 5131-5149, https://doi.org/ 10.1029/1998JC900090.

Wang, X., G. Han, Y. Qi, and W. Li, 2011: Impact of barrier layer on typhoon-induced sea surface cooling. Dyn. Atmos. Oceans, 52, 367-385, https://doi.org/10.1016/j.dynatmoce.2011.05.002.

Weller, R. A., and A. J. Plueddemann, 1996: Observations of the vertical structure of the oceanic boundary layer. J. Geophys. Res., 101, 8789-8806, https://doi.org/10.1029/96JC00206.

Willis, J. K., D. Roemmich, and B. Cornuelle, 2004: Interannual variability in upper ocean heat content, temperature, and thermosteric expansion on global scales. J. Geophys. Res., 109, C12036, https://doi.org/10.1029/2003JC002260.

Wu, Q., and D. Chen, 2012: Typhoon-induced variability of the oceanic surface mixed layer observed by Argo floats in the western North Pacific Ocean. Atmos.-Ocean, 50, 4-14, https:// doi.org/10.1080/07055900.2012.712913. 